\title{
Auxin Signaling in Regulation of Plant Translation Reinitiation
}

\author{
Mikhail Schepetilnikov* and Lyubov A. Ryabova* \\ Institut de Biologie Moléculaire des Plantes, Centre National de la Recherche Scientifique, UPR 2357, Université de \\ Strasbourg, Strasbourg, France
}

\section{OPEN ACCESS}

Edited by:

Alejandro Ferrando,

Universitat Politècnica de València,

Spain

Reviewed by:

Jin-zhi Zhang,

Huazhong Agricultural University,

China

Hsu-Liang Hsieh,

National Taiwan University, Taiwan

*Correspondence:

Mikhail Schepetilnikov

mikhail.shchepetilnikov@ibmp-

cnrs. unisra.fr

Lyubov A. Ryabova

lyuba.ryabova@ibmp-cnrs.unistra.fr

Specialty section:

This article was submitted to

Plant Physiology,

a section of the journal

Frontiers in Plant Science

Received: 30 March 2017

Accepted: 26 May 2017

Published: 14 June 2017

Citation:

Schepetilnikov $M$ and Ryabova LA (2017) Auxin Signaling in Regulation of Plant Translation Reinitiation.

Front. Plant Sci. 8:1014.

doi: 10.3389/fpls.2017.01014
The mRNA translation machinery directs protein production, and thus cell growth, according to prevailing cellular and environmental conditions. The target of rapamycin (TOR) signaling pathway-a major growth-related pathway-plays a pivotal role in optimizing protein synthesis in mammals, while its deregulation triggers uncontrolled cell proliferation and the development of severe diseases. In plants, several signaling pathways sensitive to environmental changes, hormones, and pathogens have been implicated in post-transcriptional control, and thus far phytohormones have attracted most attention as TOR upstream regulators in plants. Recent data have suggested that the coordinated actions of the phytohormone auxin, Rho-like small GTPases (ROPs) from plants, and TOR signaling contribute to translation regulation of mRNAs that harbor upstream open reading frames (UORFs) within their $5^{\prime}$-untranslated regions (5'-UTRs). This review will summarize recent advances in translational regulation of a specific set of UORF-containing mRNAs that encode regulatory proteins - transcription factors, protein kinases and other cellular controllers - and how their control can impact plant growth and development.

Keywords: target of rapamycin TOR, small GTPases ROPs, S6K1, endosomes, signal transduction, translationreinitiation

\section{INTRODUCTION}

Plant hormones (phytohormones) trigger complex growth and developmental processes. One of the most important plant growth regulators is auxin (from the Greek "auxein" meaning to enlarge/grow) - a small signaling molecule with great ability to induce growth responses throughout the plant life cycle. The auxin signaling pathway modulates diverse aspects of plant growth and development, such as responses to light and gravity, organ patterning, general root and shoot architecture and vascular development. Auxin elicits responses-cell division and expansion-depending on the cellular and developmental context in which it is perceived. The core components of auxin signaling differ in their expression patterns due to transcriptional and posttranscriptional regulation. Here, we review recent data describing auxin signaling in the cytoplasm of plant cells, and how auxin perception leads to activation of target of rapamycin (TOR), which promotes a protein synthesis pathway. In eukaryotes, TOR signaling is a key signaling pathway connecting environmental signal perception to growth decisions. Thus, TOR is a sensor that upregulates cell growth and proliferation but also limits life span in yeast, mammals and plants. A hypothetical scheme linking auxin and TOR signaling with the G-protein (guanine nucleotidebinding proteins) family is described. This observation makes TOR an important part of the auxin signaling pathway that up-regulates translation, and, thus, plant growth and development. 
It is clear that many environmental cues, such as nutrient and energy availability, instruct phytohormones to control plant growth, making it a very plastic process. We decided to travel along the recently discovered pathway from auxin to TOR via a small GTPase, ROP2, which ends by up-regulating production of critical effector proteins using a post-transcriptional mechanism via targeting of a specific translation initiation pathway: reinitiation.

\section{AUXIN PERCEPTION AND SIGNALING}

Auxin distribution is highly regulated in plants. Local auxin maxima and concentration gradients drive cell differentiation and embryogenesis. Auxin patterns form dynamically in response to environmental inputs (e.g., light and gravity). Thus auxin signal is converted into context-dependent developmental responses. Auxin perception is believed to be mediated by receptors that physically bind auxin, allowing it to travel from outside the cell into the cell cytoplasm, where it then initiates signal transduction cascades that trigger specific physiological auxin responses.

The best-characterized auxin pathway targets the nucleus (Mockaitis and Estelle, 2008), whereas the cytoplasmic role of auxin remains unexplored despite the existence of cytoplasmic auxin networks in the ER and plasma membranes (PMs) (Friml and Jones, 2010). The classical nuclear auxin signaling pathway relies on a molecular mechanism of action via auxin-dependent degradation of the transcriptional repressors Aux/IAA, which leads to gene activation outputs depending on the cellular spatio-temporal context. This degradation is dependent on the ubiquitin ligase Skp1-Cullin-F-box (SCF) ${ }^{\mathrm{TIR} 1}$ protein complex, where the associated F-box protein TIR1 confers target specificity (Lavy and Estelle, 2016). In the presence of auxin, the F-box protein TIR1 binds to Aux/IAA, resulting in the ubiquitination and degradation of the latter (Gray et al., 2001). By filling in a hydrophobic cavity at the protein interface, auxin enhances TIR1-substrate interactions by acting as a "molecular glue" (Tan et al., 2007). In this context, F-box protein TIR1 is a true auxin receptor, mediating transcriptional responses to auxin in plants (Dharmasiri et al., 2005; Kepinski and Leyser, 2005). Each TIR receptor targets specific Aux/IAA proteins for degradation (Parry et al., 2009), thus switching on transcription of a multitude of genes, including auxin response factors (ARFs). The ARF transcription factors (23 members in Arabidopsis) contain DNA binding domains and interact specifically with tandem repeats, known as Auxin-Responsive Elements (AuxREs; Ulmasov et al., 1995, $1997 \mathrm{a}, \mathrm{b})$ that serve as either activators or repressors of transcription. ARFs regulate a multitude of critical steps in plant development by converting local auxin maxima into gene expression responses. Several ARF genes confer developmental phenotypes, and some possess interaction complexity and functional overlap. One example is ETTIN/ARF3, which is involved in establishment of organ polarity (Sessions et al., 1997; Garcia et al., 2006; Marin et al., 2010; Kelley et al., 2012). Recent data suggest the existence of a non-canonical direct auxin effect on ETTIN without the ubiquitination and Aux/IAAmediated degradation steps (Simonini et al., 2016), thus raising the question of whether alternative auxin pathways can exist. Another well-studied example of a transcription-activating ARF is MONOPTEROS/ARF5 (MP). Defects in MP result in aberrant seedling morphology, often with a single cotyledon and a loss of basal structures (Hardtke and Berleth, 1998). Current data indicate that ARF protein levels are regulated posttranscriptionally (Nishimura et al., 2005; Leyser, 2006; Zhou et al., 2010).

Auxin Binding Protein 1 (ABP1), which displays high affinity to chlorinated auxins (Reinard et al., 1998; Napier et al., 2002), was characterized as an auxin receptor and implicated in many aspects of growth and development, particularly mediating the fast, non-genomic effects of auxin (for a review, see Chen and Yang, 2014). Specifically, ABP1 was implicated in rapid cell surface-located auxin signaling as a sensor of cytosolic $\mathrm{pH}$ and $\mathrm{K}^{+}$flux (Thiel et al., 1993; Gehring et al., 1998). Although $\mathrm{ABP} 1$ is a soluble auxin receptor, its partnering with membrane associated-receptor-like kinase TMK (transmembrane kinase) was proposed for perception of auxin and its travel to the cytoplasm (Xu et al., 2014). In 2015, however, several publications raised significant concerns about the role of ABP1 in both auxin signaling and Arabidopsis development (Gao et al., 2015; Strader and Zhao, 2016).

Since auxin efflux carriers bind auxin and promote its polar active transport (PAT) from cell to cell, it was suggested that the PIN-FORMED (PIN) family of auxin efflux carriers could be considered as auxin receptors (Hertel, 1995). PINs orchestrate polar cell-to-cell auxin transport via asymmetric subcellular concentrations. Moreover, PINs were implicated in the formation of auxin perception complexes when partnered with PID (PINOID) protein kinases (for a review, see Strader and Zhao, 2016). However, since PINs are not able to generate secondary messengers or the intermediate reactions required for signal transduction, this idea seemed to be non-productive. Interestingly, several PINs, including PIN5 and PIN8, are involved in cytoplasmic auxin trafficking, where PIN5 likely mediates auxin transport from the cytosol into the lumen of the ER (Mravec et al., 2009), and PIN8 from the ER to the cytosol (Ding et al., 2012). PIN8 is highly expressed during pollen development, and resides in the ER of pollen grains and germinated tubes (Bosco et al., 2012; Ding et al., 2012). Although PIN8 specific expression resulted in shorter root hairs likely due to auxin efflux activities that decrease accumulation of auxin, overexpression of PIN5 promotes root hair growth by increasing levels of internal auxin in the root hair cells (Ganguly et al., 2010). Therefore, both PIN5 and PIN8 can mediate auxin trafficking within the cytosol and the ER, but their output effects require further studies.

Auxin can alter plant development rapidly in response to different environmental stimuli acting at many diverse downstream target systems. In the cytoplasm, auxin is able to activate PM-associated ROPs (Rho-like GTPases from plants), which are involved in the regulation of endocytosis of auxin transport proteins and organization of the cytoskeleton (Tao et al., 2002). Although ROPs, as powerful signaling 
molecules, coordinate many diverse signal transduction pathways, accumulating data suggest clearly defined crosstalk between auxin and ROP signaling (Tao et al., 2002; Xu et al., 2010; Schepetilnikov et al., 2017). ROP GTPases function as mediators of auxin-regulated gene expression, rapid PM auxin signaling, and directional auxin transport to link local auxin gradients with ROP regulation of cell polarity (for a review, see Wu et al., 2011). In Arabidopsis, ROPs are encoded by 11 genes that comprise a closely related, multigenic family that represents a subgroup of the Ras superfamily of small GTPases, and includes Rho, Rac, and Cdc42 subfamilies (Winge et al., 2000). Like other G-proteins, ROPs interact with their target proteins through conformation-specific states: a GTP-bound active state, a short-lived nucleotide free state, and a GDPbound inactive state (Berken and Wittinghofer, 2008). ROPs efficiently bind GTP, but their hydrolysis activity depends on Rho GTPase-activating proteins RopGAPs (Berken et al., 2005; Gu et al., 2006; Berken and Wittinghofer, 2008). Plants contain a family of RhoGAPs that carries a conserved GAP-related domain and an N-terminal CRIB (Cdc42/Rac-interactive binding) motif that is involved in ROP binding (Wu et al., 2000), and REN1 (ROP1 ENHANCER1) protein, which, in addition to a GAPrelated domain, carries an $\mathrm{N}$-terminal pleckstrin homology $(\mathrm{PH})$ domain (Hwang et al., 2008). Both RopGAPs have been shown to regulate ROP signaling (Wu et al., 2000; Klahre and Kost, 2006; Hwang et al., 2008). In contrast, guanine nucleotide exchange factors (RopGEFs) activate ROPs by promoting GDP-GTP recycling. The Arabidopsis genome contains a single ortholog of the mammalian DOC180 family protein, SPIKE1 (SPK1; Qiu et al., 2002), and 14 plant-specific RopGEF family members with the PRONE (plant-specific Rop nucleotide exchanger) domain required for GTP-GDP exchange (Berken et al., 2005; $\mathrm{Gu}$ et al., 2006). Several ROP downstream effectors-a family of CRIB-domain-containing proteins (RICs) that specifically interact with active GTP-bound ROPs-have been described in plants (Nagawa et al., 2010; Fehér and Lajkó, 2015). Although RICs are highly variable, their CRIB motifs are highly conserved (Nagawa et al., 2010), and the CRIB motif is used widely to estimate active ROP levels using a pull-down assay with a ROP-interactive CRIB motif-containing protein 1 (Ric1) that specifically targets activated forms of RAC/ROPs (Tao et al., 2002).

Although the role of the auxin signal transduction pathway in ROP signaling activation has been well documented, mechanisms and intermediate signaling components are not well known. Since RopGEFs are defined as molecules that activate ROPs, while RopGAPs prevents uncontrolled signaling of ROPs, both could be potential components of the auxin-ROP signaling axis. The PM localized receptor-like protein kinases (RLKs) play a critical role in transmission of extracellular signals to intracellular ROP signaling pathways, and function in regulation of fertilization and cell expansion mechanisms such as cell elongation, tip and hair growth (for a recent review, see Galindo-Trigo et al., 2016). We draw the reader's attention to the Catharanthus roseus RLK-1-like (CrRLK1L) protein kinase subfamily, which contains FERONIA (FER; Hématy and Höfte, 2008). FER specifically up-regulates ROP2 signaling activity through RopGEFs in Arabidopsis (Duan et al., 2010); the FER and RopGEF-containing complex recruits an inactive form of ROP2 and converts it to an active form in a guanine nucleotide-responsive manner, while fer mutants accumulate the inactive (GDP) form of ROP2 (Duan et al., 2010). Moreover, it was suggested that a network of different RLKs, RhoGEFs, and ROPs can respond to diverse signals in various tissue and cell types (Schiller, 2006). Importantly, FER protein kinase interferes with several phytohormone pathways, including auxin signaling (Duan et al., 2010). Although auxin signaling stimulates root hair elongation (Pitts et al., 1998; Rahman et al., 2002), root hairs of fer mutants are not responsive to exogenous application of auxin (Duan et al., 2010). Taking into account that loss-of-function fer mutants are pleiotropic and display severe growth defects, FER is indispensable for plant growth and development (Duan et al., 2010). Future research will determine whether FER and RopGEFs function in ROP signaling control in an auxin-sensitive manner. Generally, RLKs can have broad functions in regulating cytoskeletal organization, vesicle trafficking and reactive oxygen species (ROS) production during plant growth (Wolf and Höfte, 2014).

\section{TOR SIGNALING COMPLEXES AND THEIR UPSTREAM REGULATION}

Cell growth requires protein synthesis-a process that consumes a huge amount of energy and therefore needs to be tightly regulated to keep a balance between cell demands and resources. Plants and animals share a common signaling pathway-the TOR pathway-connecting growth with environmental signal perception, where TOR accomplishes fine-tuning of the translational machinery, thus reprogramming translation rates in accordance with cellular needs. TOR operates as a hub in the signal transduction network that coordinates many critical molecular processes in eukaryotes, such as translation, proliferation, transcription, survival, aging, differentiation and autophagy, and is responsive to diverse signals, including nutrient and oxygen availability, energy sufficiency, stress, hormones, and growth factors. For two recent excellent reviews on the TOR signaling pathway in plants (see Barrada et al., 2015; Dobrenel et al., 2016).

Target of rapamycin belongs to the family of phosphatidylinositol kinase-related kinases (PIKKs), and is clearly related to PIK. However, TOR is atypical of PIK in that it appears not to phosphorylate lipid substrates, instead possessing a serine-threonine protein kinase activity. TOR was first described in yeast over 20 years ago as a target protein of the anti-fungal and immunosuppressant agent rapamycin (Heitman et al., 1991; Kunz et al., 1993). Rapamycin is a naturally occurring macrolide that acts as an allosteric inhibitor of TOR. Rapamycin forms a drug-receptor complex with the cellular peptidyl-prolyl cis-trans isomerase FKBP12, which, upon binding to TOR, inhibits its kinase activity (Sabatini et al., 1994; Choi et al., 1996). In contrast, most plants are insensitive to rapamycin-mediated inhibition of growth due to FKBP12, which is not efficient in rapamycin binding (Xu et al., 1998; Mahfouz et al., 2006; Sormani et al., 2007; Deng et al., 2016). 
Mammalian TOR (mTOR) exists in two multiprotein complexes, mTORC1 and mTORC2, which differ in their composition, function, downstream substrates, and mode of action (direct or indirect) in many cellular processes. mTORC1 contains the TOR catalytic subunit, scaffold protein Raptor (regulatory associated protein of TOR), adaptor mLst8 (lethal with SEC13 protein 8 ) and regulatory protein DEPTOR (DEP domain-containing TOR-interacting). The mTORC2 complex-larger in size, with a molecular weight of about $1.4 \mathrm{MDa}-$ contains TOR, scaffold protein Rictor (rapamycin-insensitive companion of TOR), mLst8, hSin1 (stress-activated protein kinase-interacting protein 1), PROTOR (protein observed with Rictor) and DEPTOR. mTORC1 is typically defined by a specific component, Raptor, and stimulates anabolic processes, including protein synthesis (Ma and Blenis, 2009), whereas mTORC2 contains Rictor and regulates cytoskeletal organization and survival (Hara et al., 2002; Kim et al., 2002; Loewith et al., 2002). mTORC2 is activated by the ribosome, where TORC2-ribosome interaction is a likely conserved mechanism that is physiologically relevant in both normal and cancer cells (Zinzalla et al., 2011). In addition, under most conditions, mTORC1 is sensitive to rapamycin, but mTORC2 is not (Loewith et al., 2002).

Plants depend greatly on signal perception by TOR (the Arabidopsis genome contains a single essential TOR gene; Menand et al., 2002; Deprost et al., 2007), which is required to adapt growth and development rapidly to changes in environmental inputs (Figure 1). The TOR pathway is a major growth regulator in plants. Previous research with transgenic Arabidopsis plants characterized by increased or decreased TOR cellular levels (Deprost et al., 2007) revealed a correlation between both root and shoot growth and TOR expression levels, thus confirming a role of TOR in growth regulation. Mutations in the TOR gene is lethal, and cause an early block in embryo development (Menand et al., 2002; Deprost et al., 2005). The Arabidopsis genome encodes two copies each of Raptor and Lst8 genes. The Arabidopsis ortholog of Raptor contains HEAT repeats and WD40 domains responsible for protein-protein interactions, and serves as a binding partner of TOR in complex assembly (Anderson et al., 2005; Deprost et al., 2005). Lst8 consists of seven WD40 repeats, which form a propeller-like structure. Disruption of Lst8 results in growth retardation phenotypes and extreme sensitivity to shifts in light conditions (Moreau et al., 2012). Recent data suggest that TOR signaling also affects cell wall biogenesis (Leiber et al., 2010) and negatively regulates autophagy in plants (Liu and Bassham, 2010; Zvereva et al., 2016) - a protein degradation process by which cells recycle cytoplasmic content under stress conditions or during senescence. The great enigma of plant TOR biology is the existence of a TORC2 complex, since no homologs of Rictor and Sin 1 have been found in the genomes mono- or dicotyledonous plants to date. A search for TOR complex subunit paralogs revealed broad conservation, with a surprising lack of TORC2 in plants and some parasites (Dam et al., 2011; Dobrenel et al., 2016). Unlike TORC2, TORC1 shows a high degree of functional conservation in both multicellular plants and unicellular algae, as manifested by TOR proteinprotein interaction experiments (Mahfouz et al., 2006; DíazTroya et al., 2008; Moreau et al., 2012).
In mammals, hormones and growth factors can directly activate mTOR signaling via phosphorylation of membrane-bound receptor kinases. Binding of insulin-a major energy control hormone-to receptor tyrosine kinase (RTK) triggers recruitment and phosphorylation of insulin receptor substrate (IRS) adaptors. IRSs activate phosphatidylinositol-3-kinase (PI3K) to generate phosphoinositol (3,4,5)-triphosphate (PIP $)$ (Burke and Williams, 2015). $\mathrm{PIP}_{3}$ binds plekstrin homology $(\mathrm{PH})$ domain and mediates the phosphoinositide-dependent kinase 1 (PDK1) and AKT kinase recruitment to the $\mathrm{PIP}_{3}$-containing compartments in the PM (Pearce et al., 2010). PDK1-activated AKT phosphorylates TSC2 to inhibit the TSC complex by inducing its release from the lysosome (Alessi et al., 1997). The TSC complex functions as a GAP for Ras homolog enriched in brain (Rheb) small GTPase (Inoki et al., 2003). Rheb is located within the lysosomal compartment, where GTP-loaded Rheb activates mTORC1 via direct interaction with the catalytic domain of mTOR (Long et al., 2005). Availability of nutrients, in particularly amino acids, promotes mTORC1 activity via the conserved Rag family of small GTPases (González and Hall, 2017).

Due to their autotrophic lifestyle, plants lack several key upstream effectors of the TOR complex (e.g., TSC, AKT, and several classes of PI3K). In plants, the most critical environmental input comes from light energy, and suppression of TOR activity negatively affects light-energy-dependent growth (Ren et al., 2012). Upon nutrient deprivation conditions, TOR activity in plants is modulated via potential antagonistic crosstalk with SnRK1 kinase (sensor of cellular energy homeostasis) (Nukarinen et al., 2016); light and sugar signaling through TOR maintain the balance between hormone-promoted growth and carbon availability (Xiong et al., 2013; Dong et al., 2015). Active TOR promotes accumulation of the brassinosteroid-signaling transcription factor BZR1 in response to environmental signals and hormones (Zhang et al., 2016). Thus, TOR kinase represents an evolutionary conserved regulator of metabolism. In plants, disruption of the TOR signaling pathway affects sugar metabolism (Dobrenel et al., 2013). TOR senses and transduces photosynthesis-derived signals to specifically control root meristem proliferation. Glucose promotes primary root and root hair growth via the TOR pathway (Xiong and Sheen, 2012). Glucose-TOR signaling was implicated in transcriptional control of the cell cycle (Xiong et al., 2013).

Another integral part of the mammalian machinery that stimulates mTOR is phospholipase D (PLD) (Wiczer and Thomas, 2012). PLD enzymes harbor a phospholipid-binding Pox domain (PX) and catalyze the hydrolysis of phosphatidylcholine to phosphatidic acid (PA). PA is a metabolite and secondary lipid messenger, which regulates response to growth factors, stress and nutrients. In response to nutrients, PI3K generates PI3P species, which interact with the PX domain of PLD and promote production of PA. PA binds the FRB (FKBP12-rapamycin binding) regulatory domain of mTOR and displaces the DEPTOR subunit from mTOR to rapidly activate mTORC1 (Fang et al., 2001; Yoon et al., 2015). In plants, PLD mediates stress responses and signal transduction. 


\section{Upstream of mammalian TOR}

\section{Upstream of plant TOR}
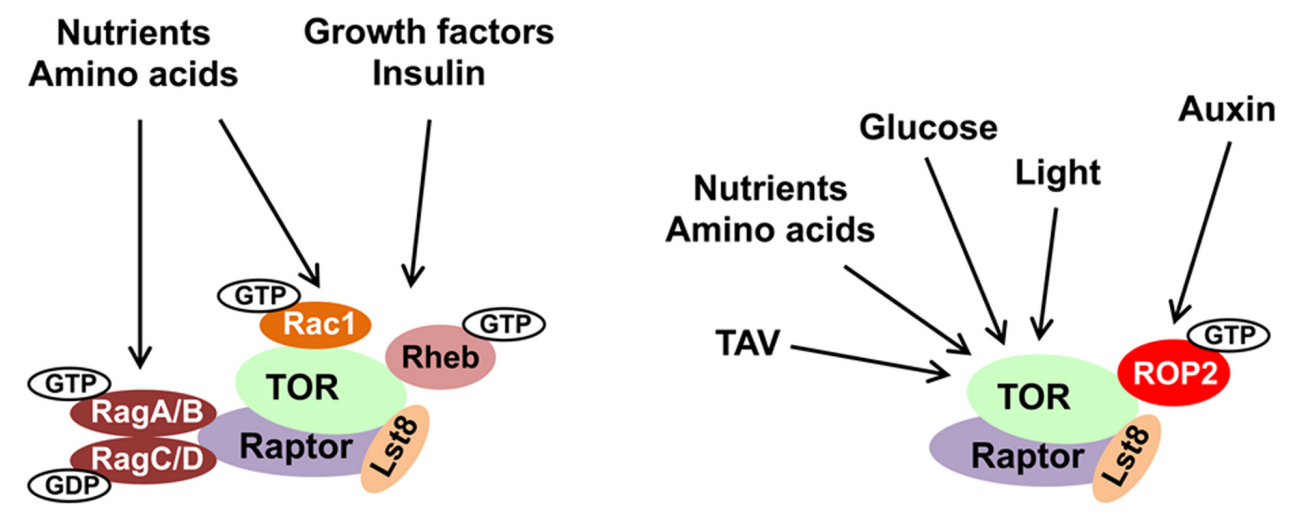

FIGURE 1 | Evolutionary conservation of upstream TOR signaling pathway in plants and animals. The main inputs upstream of TOR are depicted. TOR, Raptor and Lst8 form the core of the TORC1 complex and are conserved in all eukaryotes. Small GTPases represent the best described regulators of TOR kinase. See text for details and abbreviations.

Plant TOR can be a key potential target of PA messengers produced by PLD. Changes in lipid composition and membrane integrity upon various abiotic stresses provoke PLD activity (Bargmann and Munnik, 2006). PA-mediated stomatal closure, root growth, tolerance to salinity and water deficits are the subjects of intensive research in plant science. In plants, PLD is induced by the stress hormone abscisic acid (Jacob et al., 1999). The involvement of PLD in ABA responses raises intriguing questions as to the potential role of abiotic stress and abscisic acid in TOR activation. Moreover, the TOR signaling pathway is involved in the regulation of ABA levels in Arabidopsis (Kravchenko et al., 2015). Strikingly, PLD and PA are required for auxin responses, providing hints of crosstalk between auxin and phosphatidylinositol signaling pathways (Li and Xue, 2007). There is now a growing body of evidence demonstrating that TOR acts as an essential factor for auxin signal transduction in Arabidopsis (Schepetilnikov et al., 2013; Dong et al., 2015; Deng et al., 2016). Auxin has been also identified as the cellular candidate for a role as an upstream TOR effector (Schepetilnikov et al., 2013). In response to auxin signaling, the TOR pathway is activated as manifested by phosphorylation of the $40 \mathrm{~S}$ ribosomal S6 kinase 1 (S6K1; a direct downstream target of TOR) at TOR-responsive Thr449, and association of active TOR with polyribosomes. Recently, glucose and light signals as well as exogenously applied auxin were shown to activate S6K1, in shoot meristems (Li et al., 2017).

Phosphorylation is a common post-translational modification that indicates an active status of mTOR kinase. Only three phospho-sites have been reported to date in mTOR (Ser 1261, 2448, and 2481; Acosta-Jaquez et al., 2009). A Rheb-driven phosphorylation event at mTOR Ser1261 within the HEAT repeat domain promotes autokinase activity at Ser2481, resulting in mTOR activation, while the C-terminal Ser2448 is likely phosphorylated by S6K1 via a feedback loop. Mapping of orthologous phosphorylation sites in Arabidopsis reveals the high conservation of mammalian Ser2448 and plant Ser2424 epitopes (Schepetilnikov et al., 2013). To date, Ser2424 is the only the TOR specific phospho-site with a confirmed biological function in auxin and ROP2 signaling (Schepetilnikov et al., 2013, 2017).

Many animal viruses have developed multiple mechanisms to activate mTOR signaling in favor of viral replication cycles. One such strategy results in stimulation of the PI3K-AKT pathway upstream of TOR kinase (for a review, see Walsh et al., 2013). The plant pararetrovirus, Cauliflower mosaic virus (CaMV), appears to be the first among plant and mammalian viruses known to trigger TOR activation (Schepetilnikov et al., 2011). Indeed, viral transactivator/viroplasmin (TAV) protein binds TOR directly, triggering its activation and recruitment to polysomes. TAV represents a unique example of a pathogenicity effector that specifically targets a basal defense system of plants and suppresses innate immune responses to non-viral pathogens in a TORdependent manner (Zvereva et al., 2016).

\section{SMALL GTPases CONTROL THE FUNCTION AND LOCALIZATION OF TOR COMPLEXES}

The molecular mechanism of TOR activation is complex and diverse. Small GTPases emerge as the most significant direct upstream regulators of TOR complexes, and function as molecular switches, which, upon activation, interact with downstream effectors and stimulate multiple signaling pathways (Table 1). It is well established that yeast and mTOR are regulated by a plethora of small GTPases, including Rho, Rheb, Rag, Rac, Ral, Arf, and Rab, each responsible for perception of a unique type of stimulus. In mammals, small GTPases from the Rheb and Rag families are the two main direct upstream regulators of TOR complexes. Mammalian TORC1 is controlled primarily by Rheb GTPase. However, activation of mTORC1 in 
TABLE 1 | Small GTPase regulators of TOR complexes.

\section{GTPase}

Ras family (signal transduction)

Rheb

Ras-homolog enriched in brain (Rheb) small GTPase is essential for mTORC1 activation. Rheb binds TOR directly. Rheb is not involved in TOR recruitment-this function is provided by Rags, which presents TOR to Rheb for proper activation. Rheb must be in a GTP-bound state to activate TOR (Long et al., 2005).

RalB

In response to nutrients, RalB GTPase activates mTORC1. RalB functions downstream of Rheb, suggesting cross-talk between amino acid-sensing signaling pathways (Maehama et al., 2008; Martin et al., 2014).

\begin{tabular}{ll}
\hline Rap1 & In amoeba, Rap1 GTPase binds directly the regulatory subunit of Sin1 and activates TORC2 (Khanna et al., 2016). \\
\hline RasC & In yeast and slime molds, RasC GTPase activates the TORC2 complex (Cai et al., 2010; Charest et al., 2010). \\
\hline Rit1 & In response to oxidative stress, Rit1 GTPase binds and activates mTORC2 (Cai and Andres, 2014).
\end{tabular}

Ras related family (signal transduction)

$\operatorname{Rag} \mathrm{A} / \mathrm{B} / \mathrm{C} / \mathrm{D}$

Rag GTPases form a heterodimer RagA/B ${ }^{\text {GTP }}$ and RagC/D GDP. Rags function as a central regulator of mTORC1 activation in response to amino acids via TOR complex recruitment to lysosomal membranes. Rags interact directly with the Raptor subunit of the mTORC1 complex. Proper GTP/GDP charging is crucial for their functioning (Kim et al., 2008; Sancak et al., 2008).

\section{Rho family (signal transduction) Rac1}

Rac1 activates both mTORC1 and mTORC2 complexes. Rac1 binds directly to TOR via its C-terminal positively charged lysine-rich motif. Rac1 recruits TOR complexes to the plasma membrane in a GTP-independent manner (Saci et al., 2011).

Rho1

In response to stress, Rho1 GTPase binds directly to the N-terminal domain of the Raptor subunit, resulting in inhibition of TORC1 activity. In yeast, Rho1 is a negative regulator of TOR activity. Rho1 disrupts membrane association of TORC1 (Yan et al., 2012; Yang et al., 2012).

ROP/RACS

In response to auxin, ROP2 GTPase binds directly to plant TOR via its C-terminal positively charged lysine-rich motif, which is similar to mammalian Rac1. GTP-bound active ROP2 recruits TOR complex on the membranes of early endosomes, which is similar to RAGs. ROP2-TOR interaction is indispensable of GTP/GDP charging, GTP is required for ROP2-mediated activation of TOR, which is similar to Rheb (Schepetilnikov et al., 2017).

\section{Arf family (intracellular trafficking)} Arf1

Arf1 activates mTORC1 on lysosomes, specifically in response to glutamine (GIn). GTP binding and hydrolysis by Arf1 is required for mTORC1 activation. Arf1 signaling to mTOR is specific to Gln and independent of ER-Golgi intracellular trafficking (Jewell et al., 2015).

\section{Rab family (intracellular trafficking)}

Rab6

In yeast, Ryh1 GTPase, ortholog of mammalian Rab6, activates TORC2. In response to glucose, the GTP-bound active form of Rhy1 interacts physically with the TORC2 complex via its effector domain (Tatebe et al., 2010; Hatano et al., 2015).

response to amino acids requires GTPases of the Rag family (Sancak et al., 2008). Two heterodimeric Rag complexes (RagA/C and $\mathrm{RagB} / \mathrm{D}$ ) bind lysosomal membranes via a lysosomal adaptor RAGULATOR - a scaffold complex with GEF activity toward Rag GTPases (Bar-Peled et al., 2012). Amino acids promote the reciprocal charging of RagA/C and RagB/D with GTP and GDP, respectively, and their binding to mTORC1 via Raptor to relocate mTORC1 to lysosomes for mTORC1 presentation to GTP-bound Rheb (Kim et al., 2008; Sancak et al., 2008). Interestingly, Rac1, a member of the Rho family of small GTPases, affects signaling through both $\mathrm{mTORC} 1$ and mTORC2 complexes. Rac1 regulates TOR intracellular localization: upon serum stimulation, Rac1 binds mTOR directly via its C-terminal, lysine-rich motif in a GTP-independent manner and governs its movement from the perinuclear region to the PM (Saci et al., 2011). Thus, Rac1-mediated mTOR activation is independent of the PI3K-AKT-TSC axis. This is opposite to Rheb GTPase, which must be in the GTP-bound state to activate mTOR.
Several amino acids can stimulate mTORC1 in a Rag GTPase independent manner. Glutamine-mediated mTORC1 recruitment to lysosomes requires an alternative pathway via the Arf family GTPase Arf1, which is normally involved in intracellular vesicular trafficking, and vacuolar ATPase (vATPase) (Jewell et al., 2015). Several other small GTPases have been identified as indirect upstream actors in the TOR signaling pathway. In yeast, glucose activates TORC2 via the Rab family GTPase Ryh1 (Tatebe et al., 2010; Hatano et al., 2015). Moreover, a member of the Rho GTPase family, Rit, was suggested to bind directly to the hSin1 subunit and activate the mTORC2 complex in response to oxidative stress (Cai and Andres, 2014). Recent data suggest a cross-talk between GTPases RalB and Rheb in nutrient perception and mTORC1 control (Maehama et al., 2008; Martin et al., 2014). Among many small GTPases in yeast, Rho1 GTPase of the Rho family can negatively regulate mTORC1 under stress conditions. Rhol GTPase is the master regulator of the yeast cell wall integrity (CWI) pathway that controls actin 
polarization, cell morphogenesis, and cell wall expansion (Levin, 2005). In response to environmental or intracellular stresses, Rho1 binds directly to the Raptor subunit and inhibits mTORC1 activity (Yan et al., 2012; Yang et al., 2012).

In eukaryotes, small regulatory $\mathrm{G}$ domain proteins of Ras superfamily are divided into five main families based on their structure, sequence and function: Ran GTPases function in nuclear trafficking; Rab and Arf/Sar-in intracellular vesicular trafficking; Ras and Rho family members regulate signal transduction. ROPs of plants are structurally distinct from the proteins in the Rho, Rac, and Cdc42 subfamilies of Rho GTPases of other eukaryotes (Brembu et al., 2006), but were originally defined as RACs based on sequence similarity to animal Rac GTPases. Since plants lack orthologs of Rheb and Rag GTPases, the ROP/RACs are the only candidates for plant-specific TORC1 upstream regulators. Strikingly, ROP2 interacts directly with TOR both in vivo and in vitro in a manner independent of its GTP-bound state, but it activates TOR, when bound to GTP. Accordingly, Arabidopsis plants with high endogenous auxin levels, or Arabidopsis seedlings treated by auxin, or expressing high GTP-bound ROP2 levels, are characterized by increased TOR phosphorylation (Schepetilnikov et al., 2013, 2017). As expected, TOR phosphorylation in response to auxin is abolished in rop2 rop6 ROP4 RNAi plants (Schepetilnikov et al., 2017). As expected, Arabidopsis plants expressing constitutively active GTP-bound ROP2 (CA-ROP2 line) are more resistant to TOR inhibitors, and display a significant delay in AZD-8055-sensitive suppression of primary root growth and root hair elongation (Schepetilnikov et al., 2017), as normally occurs in WT seedlings in response to this TOR inhibitor (Montané and Menand, 2013). Similarly, active GTP-bound ROP2 triggered root hair elongation, but, in addition, ROP2 up-regulation promotes initiation of additional misplaced hairs (Jones et al., 2002).

In plants, as with most small GTPases, membrane association of ROPs is mediated by post-translational modifications, including prenylation and S-acylation (Hancock et al., 1989; Li et al., 1999; Fu et al., 2005, 2009; Sorek et al., 2011), similar to that shown for members of the Ras superfamily of small G-proteins (Michaelson et al., 2001). Recent research has revealed that ROPs 1-6 and mammalian Rac1 share a common sequence motif comprising several basic lysine residues that direct interaction with TOR (Saci et al., 2011; Schepetilnikov et al., 2017). The next important issue to be resolved is the intracellular compartmentalization of TOR upon auxin treatment. The PM operates as a platform for diverse receptor signaling and vesicle trafficking events. Active GTP-bound ROPs associate closely with the PM, which allows recruitment of ROPs from the cytoplasm (Sorek et al., 2011). ROP GTPases are not known to be localized in intracellular vesicles, suggesting rather a transient association with intracellular compartments or a unique redistribution in the PM. Since ROP2 interacts physically and functionally with TOR, it may participate in TOR relocation to the PM. Interestingly, ROP2 association with PM is indispensable for subsequent TOR activation-ROP2 GTPase lacking a prenylation domain is still capable of interacting with, but not activating, TOR (Schepetilnikov et al., 2017). Phosphorylated TOR accumulates in microsomal fractions of CA-ROP2 plants, and colocalizes with endosomes in the cytoplasm in a ROP2-dependent manner. Note that the Lst8 subunit has been also found colocalized with endosomes (Moreau et al., 2012). TOR binding to endosomes is not sensitive to disruption of ER-to-Golgi intracellular vesicular trafficking, but may rely on the endocytic pathway. Primarily, ROP GTPases are considered to control cytoskeleton reorganization, thus interfering with vesicular trafficking. In response to auxin, GTPases of the ROP family coordinate the recycling of PINFORMED (PIN) transporters between the PM and endomembrane compartments (Chen and Friml, 2014). Accordingly, TOR may move to specific intracellular locations via interaction with appropriate subsets of small regulatory GTPases.

Many questions remain unanswered: what are the effects of ROP2 that increase intrinsic phosphorylation activity of TOR, and do other ROPs contribute to TOR activation? TOR complexes have been found at several subcellular locations, including the cytoplasm and the nucleus. Nevertheless, how TOR can mediate activation on lysosomes and be translocated to $40 \mathrm{~S}$ preinitiation complexes (40S PIC) to regulate the cell translation machinery is still an open question. In addition, TOR is known to be localized in mitochondria, the PM and stress granules in response to different inputs (Betz and Hall, 2013). In the unicellular green alga Chlamydomonas, TOR activity is restricted to ER membranes (Díaz-Troya et al., 2008, 2011). Further work is obviously required to examine the intracellular location and trafficking of TOR, in both active and inactive states, and whether TOR activation takes place before or after its loading on endosomes.

\section{TOR PROMOTES TRANSLATION REINITIATION IN PLANTS}

Plants are sessile organisms that continuously monitor and transduce environmental inputs into regulation of protein synthesis pathways. Indeed, much effort has been directed to demonstrate that translation of many mRNAs is affected by a multitude of environmental signals, for example, cold (Juntawong et al., 2013), heat (Matsuura et al., 2013), dehydration (Kawaguchi et al., 2004; Kawaguchi and Bailey-Serres, 2005; Park et al., 2012), salinity (Park et al., 2012), hypoxia (Branco-Price et al., 2005, 2008), and light (Khandal et al., 2009; Juntawong and Bailey-Serres, 2012; Floris et al., 2013). However, the underlying molecular mechanisms that affect protein synthesis efficiency are largely unknown and in need of further research. A recent study revealed that heat stress can rapidly induce an mRNA degradation process where involving LARPs (La and related Proteins) (Deragon and Bousquet-Antonelli, 2015). Strikingly, mammalian LARP1 was implicated in translation regulation of TOP ( $5^{\prime}$-terminal oligopyrimidine tract)-containing mRNAs under the control of TOR (Tcherkezian et al., 2014); however, whether translation of many plant TOP-containing mRNAs (Dobrenel et al., 2016) depends on TOR remains to be identified. Moreover, the contribution of TOR to the overall control of cap-dependent translation initiation via phosphorylation of eIF4E-binding proteins (4E-BPs) - the best 
studied mechanism of translation control in response to stress in other eukaryotes (Siddiqui and Sonenberg, 2015)-has been questioned in plants due to the lack of data on plant 4E-BPs. A discussion of cap-dependent translation control in plants, including a key mechanism of down-regulation of translation by phosphorylation of eIF $2 \alpha$, is beyond the scope of this review, and it is well described recently (Browning and Bailey-Serres, 2015).

Conversely, Arabidopsis plants silenced for TOR expression display significantly reduced polysomal abundance (Deprost et al., 2007), suggesting a role for TOR in plant translation. Additionally, it was reported that auxin signaling can affect translation, as manifested by phosphorylation of ribosomal protein S6 (RPS6) and up-regulation of polysomal levels in Arabidopsis suspension cultures (Beltrán-Peña et al., 2002; Turck et al., 2004). Accordingly, application of new generation TOR inhibitors, as well as existing TOR-deficient plants, has uncovered TOR function in the translation reinitiation of a specific pool of cellular mRNAs that harbor upstream open reading frames (uORFs) within their leader regions (uORFmRNAs; Schepetilnikov et al., 2013). The current model suggests that TOR can receive signals from auxin via a small GTPase ROP2 to boost production of important regulatory proteins in a post-transcriptional manner by targeting a specific translation mechanism: reinitiation (Figure 2).

Upstream open reading frames are defined as $5^{\prime}$-UTR ciselements of mRNAs defined by a start codon that is outof-frame with the main ORF. Mounting data suggest the critical importance of post-transcriptional control via translation reinitiation (Roy et al., 2010; Schepetilnikov et al., 2013; von Arnim et al., 2014). Nowadays, uORFs are considered as prevalent translation repressors in eukaryotes (Johnstone et al., 2016). This is not surprising since more than $30 \%$ of eukaryotic mRNAs harbor relatively long leaders that contain multiple uORFs (Calvo et al., 2009). Among these are ARF family of transcription factors (von Arnim et al., 2014) and human tyrosine kinases (Wethmar et al., 2016); uORFs play a role of molecular switches in pathophysiology (Wethmar et al., 2010) and in stem cell regulation and organogenesis in plants (Zhou et al., 2014). To understand how translation reinitiation is controlled by upstream signals and contributes to overall protein synthesis, we first review briefly how uORFs can alter expression of the main ORF located downstream of the leader. The scanning model of eukaryotic translation initiation states that the $40 \mathrm{~S}$ ribosomal subunit prebound by a multisubunit complex (eIF3, eIF1 and eIF1A, eIF5) and a ternary complex (TC, eIF2-GTPMet-tRNAi ${ }^{\text {Met }}$ ) loads at the capped $5^{\prime}$-end of mRNA via eIF4Fbound to cap, scans in a $3^{\prime}$-direction until it recognizes an initiation codon in a suitable initiation context, where $60 \mathrm{~S}$ joins and translation elongation begins (Browning and BaileySerres, 2015; Hinnebusch et al., 2016). The preceding translation event would negatively interfere with translation reinitiation at a downstream ORF, mainly due to loss of eIFs that have been recruited during the cap-dependent initiation event. It is generally accepted that reinitiation at the downstream AUG codon can occur, if (1) the initiation context of the $5^{\prime}$ AUG codon is not optimal and is recognized only inefficiently by scanning ribosomes (leaky scanning mechanism-Kozak, 1986), and there

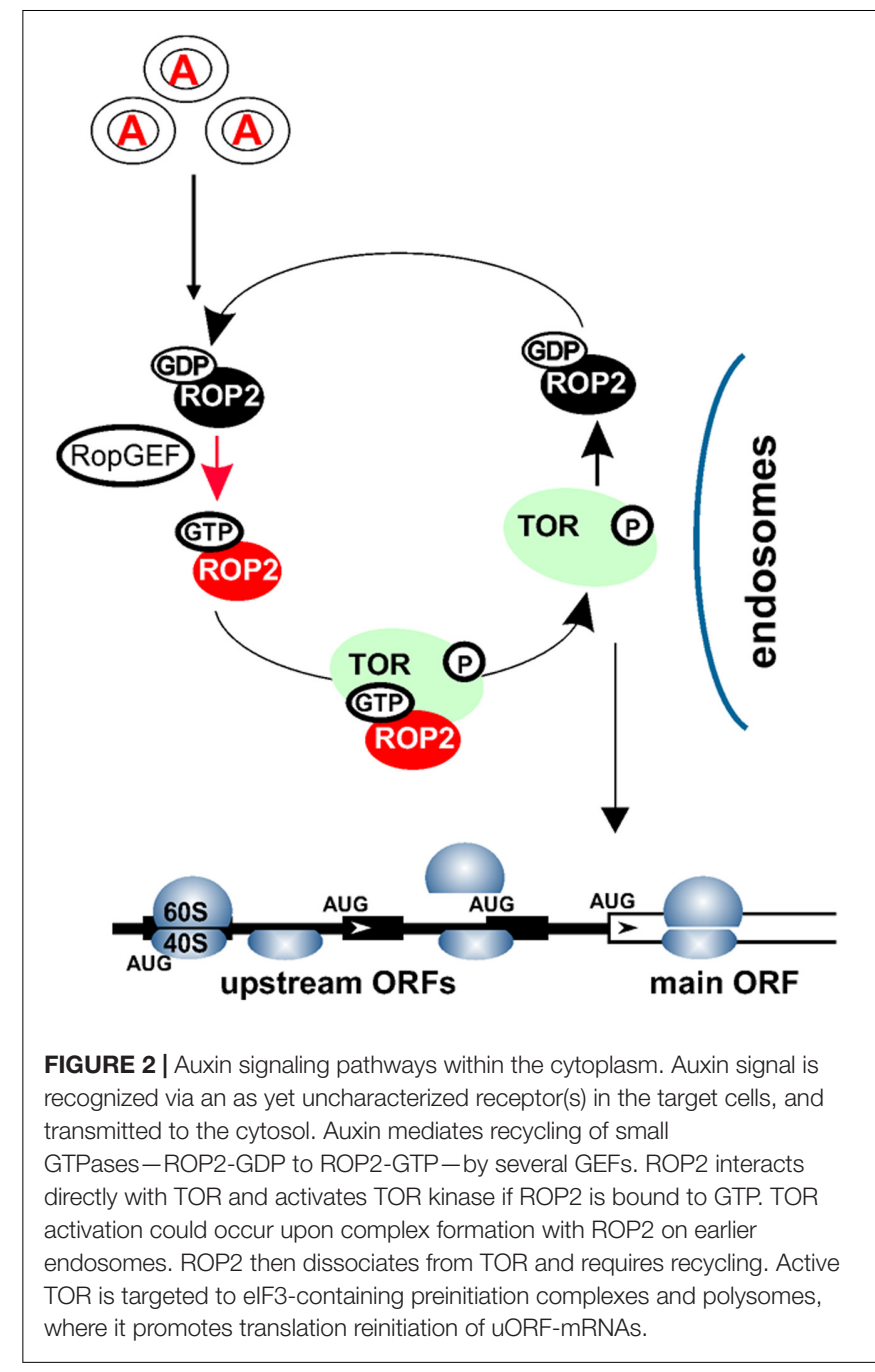

is no downstream secondary structure that would improve its recognition (Kozak, 1990); or (2) the initiation context is optimal, but is located in close proximity to the $5^{\prime}$-end of mRNA (Kozak, 1991); and (3) the preceding translation event was short (short uORF of 2 to $\sim 30$ codons) (Kozak, 1999). In the latter case, reinitiation is less efficient, but can be improved slightly by having a sufficiently long intercistronic distance between the uORF and the "main" ORF (Kozak, 1987; Luukkonen et al., 1995; Hinnebusch, 1997). The reinitiation potential of ribosomes depends on specific features of uORFs, as well as their amount and combination (von Arnim et al., 2014), and can be regulated by specific trans-acting factors (Rahmani et al., 2009; Medenbach et al., 2011).

Beside these features of $\mathrm{uORF}$, stalled translation of sequence-specific short uORFs can block translation reinitiation of a leader downstream ORF (Sachs and Geballe, 2006). Sequence-specific uORFs are common in genes involved in a variety of control mechanisms, and encode attenuator peptides that act in a sequence-dependent manner to inhibit its own translation termination, often through a delay of peptidyl-tRNA hydrolysis in response to saturating levels of a 
regulatory signal, usually a metabolite. For example, a $48-55$ codon UORF is responsible for the translational repression of the SAMDC (S-ADENOSYLMETHIONINE DECARBOXYLASE) gene in response to stress conditions and high polyamine levels (Hanfrey et al., 2005). Sequence-specific uORFs control the synthesis of AtbZIP transcription factors and several of their paralogs, as well as trehalose-6-phosphate phosphatase, in a manner sensitive to carbohydrates (Wiese et al., 2004; Hayden and Jorgensen, 2007). It seems certain that more short sequencespecific uORFs that would irreversibly abolish reinitiation of the main ORF translation in response to various regulatory signals or under certain conditions will be identified.

How does the $40 \mathrm{~S}$ terminating subunit solve the problem of rapid loading of factors necessary for the reinitiation event, i.e., Met-tRNAi ${ }^{\text {Met }}$ and $60 \mathrm{~S}$ ? The most likely explanation is that initiation factors that have been recruited during the cap-dependent initiation event dissociate from $40 \mathrm{~S}$ gradually, and might remain associated with the translating ribosome for a few elongation cycles (Kozak, 1987). These reinitiation promoting factors (RPFs) could assist 40S ribosomal subunits to resume scanning, rapidly acquire TC and 60S de novo and thus stay reinitiation-competent. A new study using in vivo RNA-protein $\mathrm{Ni}^{2+}$-pull down assay directly demonstrated that eukaryotic initiation factor 3 (eIF3) physically associates with early elongating ribosomes on the GCN4 mRNA (Mohammad et al., 2017). eIF3 is composed of 13 distinct subunits in humans and plants, and facilitates rapid recruitment of TC to $40 \mathrm{~S}$ and assembly of the $43 \mathrm{~S}$ preinitiation complex on mRNA (Burks et al., 2001; Hinnebusch, 2006). Mammalian RPFs include, in addition to eIF3 (Cuchalová et al., 2010; Munzarová et al., 2011), the cap-binding complex eIF4F (Pöyry et al., 2004).

In plants, eIF3 non-core subunit h (eIF3h) greatly elevates the reinitiation competence of mRNAs coding for the Arabidopsis basic zipper transcription factors (bZIPs) and several ARFs (Roy et al., 2010; Zhou et al., 2010); while the 60S ribosomal protein L24B (RPL24B), which is encoded by SHORT VALVE1, lifts translation of uORF-containing mRNAs that encode ARF3 (ETTIN) and ARF5 (MONOPTEROS; Nishimura et al., 2005; Zhou et al., 2010). Thanks to a mutant allele of eif $3 h-1$ carrying a C-terminally truncated eIF3h and a short valvel (stv1) mutant lacking the RPL24-encoding gene, it was demonstrated that both mutants display similar defects in auxin-mediated organogenesis and undertranslate uORF-containing bZip11 and several ARF mRNAs (Zhou et al., 2010). Although eIF3h can be dispensable for cap-dependent translation initiation (Kim et al., 2004; Roy et al., 2010), a global analysis of ribosomal loading confirmed that many mRNAs containing uORFs are less abundant in polysomes in the eif $3 h-1$ mutant (Tiruneh et al., 2013), thus confirming that translation of the majority of uORF-containing mRNAs depends on eIF3h. Future studies will clarify the mechanism of eIF3h function in reinitiation of translation.

Taken together, translation of mRNAs with several short uORFs is still possible, albeit with lowered efficiency, while reinitiation after long ORF translation is largely prohibited in eukaryotes. However, viruses often break basic cellular rules.
Indeed, there are a few abnormal cases of reinitiation after long ORF translation, best studied in mammalian caliciviruses (Royall and Locker, 2016) and plant caulimoviruses (Ryabova et al., 2006). The subgenomic mRNA of caliciviruses is bicistronic, with two long ORFs that encode structural proteins VP1 and VP2 overlapping by four nucleotides, and its translation relies on a termination-dependent reinitiation strategy, where expression of the downstream cistron is dependent on the ribosome binding site (TURBS) within the upstream VP2 ORF located close to VP1 ORF stop codon. The motif was shown to bind 40S ribosomal subunits and eIF3 (Luttermann and Meyers, 2007; Pöyry et al., 2007). Thus, in caliciviruses, the ribosome might be held at the stop/restart region by base pairing of TURBS with the 18S rRNA (Luttermann and Meyers, 2009; Zinoviev et al., 2015), and can be further stabilized by binding of eIF3 to promote reinitiation by post-terminating $80 \mathrm{~S}$ ribosomes (Pöyry et al., 2007).

The second unique example of reinitiation after long ORF translation comes from CaMV, where reinitiation critically depends on a single viral protein TAV (De Tapia et al., 1993). To promote reinitiation, TAV interacts with the host translation machinery via eIF3 (Park et al., 2001), reinitiation supporting protein (RISP; Thiébeauld et al., 2009), and TOR, where TAV activates TOR via an as yet unknown mechanism (Schepetilnikov et al., 2011). According to the current model, TAV is responsible for retention of RPFs on translating ribosomes during the long elongation event, thus increasing the reinitiation competence of ribosomes. Indeed, sucrose gradient analysis of extracts isolated from Arabidopsis plants transgenic for TAV revealed greatly increased accumulation of eIF3, RISP, and TOR in addition to TAV in polysomes as compared with WT plants (Thiébeauld et al., 2009). Moreover, TAV function in reinitiation is strongly dependent on active TOR (Schepetilnikov et al., 2011). RISP appears to be a specific target of TOR/S6K1 signaling, and its phosphorylation promotes both its binding to TAV and TAV function in translation reinitiation. Indeed, TOR and RISP binding to polyribosomes correlates with RISP phosphorylation, while phosphorylation of RISP is abolished in polysomes isolated from plants transgenic for a TAV deletion mutant that failed to associate and thus activate TOR (Schepetilnikov et al., 2011). In conclusion, it was proposed that TOR function in polysomes would be to maintain the high phosphorylation status of RISP, and possibly other RPFs, to promote viral pathogenesis.

In mammals, eIF3 was identified as a platform for phosphorylation of S6K1 by TOR, where active mTOR or inactive $\mathrm{mS6K} 1$ enter the cell translation machinery via interaction with the eIF3-containing preinitiation complex in a dynamic order of events (Holz et al., 2005). Although the eIF3 complex is prebound by inactive $\mathrm{mS6 \textrm {K } 1}$ in mTOR inactivation conditions, binding of mTOR, when it is activated, results in phosphorylation and dissociation of $\mathrm{mS6K} 1$. In yeast, TORC2 was detected in polysomes, where it maintains co-translational phosphorylation of Akt kinase (Oh et al., 2010). In Arabidopsis, TOR, when active, associates with polysomes also prebound by inactive S6K1, phosphorylates S6K1, triggering its dissociation (Schepetilnikov et al., 2011, 2013). Further phosphorylation of S6K1 may involve PDK1 (Deak et al., 1999). 
In plants, active TOR accumulates mainly within $40 \mathrm{~S}$ preinitiation complexes, and at significantly lowered levels in polysomes, which can explain the low reinitiation capacity of Arabidopsis plants. Although partial depletion of TOR revealed defects in polysomal loading of uORF-containing mRNAs that require reinitiation; TOR, when up-regulated in response to either auxin or by GTP-ROP2, promotes polysomal loading and translation of $A R F 3, A R F 5, b Z I P 11$, and other uORF-containing mRNAs (Schepetilnikov et al., 2013, 2017). Active TOR can up-regulate translation reinitiation via phosphorylation of the plant reinitiation factor eIF3h in polysomes to maintain the high phosphorylation status of eIF3h-promoting reinitiation events (Schepetilnikov et al., 2013). A new study has identified mTORC1 as the key factor contributing to translation of uORF-mRNA that encodes ATF4, a member of the CREB/ATF family of bZIP transcription factors, where TOR may regulate ATF4 mRNA translation through a uORF-dependent mechanism and 4E-BPs (Park et al., 2017).

Translation/reinitiation events within bZIP11, ARF3, and ARF5 5'-UTRs impede or block ribosomal movement toward the main ORF, causing inefficient translation of uORF-mRNAs under WT conditions (Zhou et al., 2010). Indeed, it was shown that uORFs downregulate main ORF translation for ARF5 by 15-fold, ARF3 by 2-fold (Zhou et al., 2010), and bZIP11 by 4-fold, if only uORFs 1,2 , and 4 are removed (Kim et al., 2004). Accordingly, polysomes isolated from WT Arabidopsis are deficient in loading of active TOR and bZIP11, ARF3 and ARF5 uORF-mRNAs, and their levels are not much higher than in plants grown on medium containing the TOR inhibitor AZD-8055 (Schepetilnikov et al., 2013, 2017). Here, the classic means of determining whether up-regulation of gene expression at the translational level has occurred on mRNAs via a shift of these mRNAs into the polysomal fraction is not easily applied to mRNAs that carry multiple uORFs within their long leader regions that would require reinitiation events. Indeed, the increased abundance of initiating/reinitiating 40S, and likely uORF-translating 80S, within their long leaders shifts these mRNAs toward $80 \mathrm{~S}$ or even light polysomal fractions, even when translation of the main ORF is strongly inhibited, depending on the number and arrangement of uORFs (Schepetilnikov et al., 2017). Upon introduction of TOR-activated conditions, TOR phosphorylation, and, consequently, uORF-mRNA loading into polysomes is increased (Schepetilnikov et al., 2017). Strikingly, studies of mRNA abundance across sucrose gradients in WT versus CA-ROP2 plants (Schepetilnikov et al., 2017) revealed a high proportion of uORF-mRNA (about 64-80\%) sedimenting to the top fraction of the gradient in WT conditions, while only $20-25 \%$ of uORF-mRNA remained in the top gradient fraction in CA-ROP2 conditions, regardless of the fact that total transcript levels did not differ significantly between WT and CA-ROP2 extracts. These data correlate with the high translation efficiencies of uORF-mRNAs in plant mesophyll protoplasts prepared from plants expressing high active TOR levels.

TOR up-regulation of reinitiation events could be as harmful in plants as in mammals, where up-regulation of the protein synthesizing machinery contributes to the development of cancer (Ruggero and Pandolfi, 2003). In the opposite situation of reinitiation defects, the developmental abnormalities identified in rpl24b and eif $3 h-1$ mutants are largely similar to auxin-related developmental defects (Zhou et al., 2010). Further investigation is needed to understand the roles of ROP2 in TOR activation, as well as to identify other upstream TOR effectors in plants and their roles in translation.

\section{CONCLUSION AND PERSPECTIVES}

The last 10 years have witnessed striking advances and rapidly emerging data on the composition of the TOR complex, the TOR pathway, and its function and control in plants, in part due to the appearance of a new generation of TOR inhibitors that bind to the TOR kinase domain within the ATP-binding pocket and inactivate TOR (Chresta et al., 2010; Montané and Menand, 2013). Many critical questions remain unanswered. Recent work has revealed the role of TOR in sensing environmental conditions, including various stresses and phytohormones, but the molecular mechanisms underlying these signaling events remain unknown. It is not yet known whether, and how, TOR controls general translation by sensing amino acid levels. Finally, a key issue is the existence of functional ortholog of TORC2 in plants. Recent data have revealed that the molecular composition of the TOR complex varies in different cell types. Identification of a novel binding partner of TOR-GIT1 (G-protein-coupled receptor kinase-interacting protein 1)-suggested a unique mTOR complex lacking both Raptor and Rictor (Smithson and Gutmann, 2016). Therefore plants can contain more than one functional TOR complex. A challenge for future studies in plants will be to elucidate further TOR signaling pathways in plant translation, and to reveal how TOR can control mRNA translation at the initiation step.

\section{AUTHOR CONTRIBUTIONS}

All authors listed, have made substantial, direct and intellectual contribution to the work, and approved it for publication.

\section{FUNDING}

Work in this laboratory on the auxin-ROP2-TOR signaling axis is supported by French Agence Nationale de la Recherché-BLAN2011_BSV6 01003 and ANR-14-CE19-0007 (all to LR). 


\section{REFERENCES}

Acosta-Jaquez, H. A., Keller, J. A., Foster, K. G., Ekim, B., Soliman, G. A., Feener, E. P., et al. (2009). Site-specific mTOR phosphorylation promotes mTORC1mediated signaling and cell growth. Mol. Cell. Biol. 29, 4308-4324. doi: 10.1128/ MCB.01665-08

Alessi, D. R., James, S. R., Downes, C. P., Holmes, A. B., Gaffney, P. R., Reese, C. B., et al. (1997). Characterization of a 3-phosphoinositide-dependent protein kinase which phosphorylates and activates protein kinase Balpha. Curr. Biol. 7, 261-269. doi: 10.1016/S0960-9822(06)00122-9

Anderson, G. H., Veit, B., and Hanson, M. R. (2005). The Arabidopsis AtRaptor genes are essential for post-embryonic plant growth. BMC Biol. 3:12. doi: 10.1186/1741-7007-3-12

Bargmann, B. O. R., and Munnik, T. (2006). The role of phospholipase D in plant stress responses. Curr. Opin. Plant Biol. 9, 515-522. doi: 10.1016/j.pbi.2006.07. 011

Bar-Peled, L., Schweitzer, L. D., Zoncu, R., and Sabatini, D. M. (2012). Ragulator is a GEF for the rag GTPases that signal amino acid levels to mTORC1. Mol. Cell. 150, 1196-1208. doi: 10.1016/j.cell.2012.07.032

Barrada, A., Montané, M. H., Robaglia, C., and Menand, B. (2015). Spatial regulation of root growth: placing the plant TOR pathway in a developmental perspective. Int. J. Mol. Sci. 16, 19671-19697. doi: 10.3390/ijms160819671

Beltrán-Peña, E., Aguilar, R., Ortíz-López, A., Dinkova, T. D., and De Jiménez, E. S. (2002). Auxin stimulates S6 ribosomal protein phosphorylation in maize thereby affecting protein synthesis regulation. Physiol. Plant. 115, 291-297. doi: 10.1034/j.1399-3054.2002.1150216.x

Berken, A., Thomas, C., and Wittinghofer, A. (2005). A new family of RhoGEFs activates the Rop molecular switch in plants. Nature 436, 1176-1180. doi: 10.1038/nature03883

Berken, A., and Wittinghofer, A. (2008). Structure and function of Rho-type molecular switches in plants. Plant Physiol. Biochem. 46, 380-393. doi: 10.1016/ j.plaphy.2007.12.008

Betz, C., and Hall, M. N. (2013). Where is mTOR and what is it doing there? J. Cell Biol. 203, 563-574. doi: 10.1083/jcb.201306041

Bosco, C. D., Dovzhenko, A., Liu, X., Woerner, N., Rensch, T., Eismann, M., et al. (2012). The endoplasmic reticulum localized PIN8 is a pollen-specific auxin carrier involved in intracellular auxin homeostasis. Plant J. 71, 860-870. doi: 10.1111/j.1365-313X.2012.05037.X

Branco-Price, C., Kaiser, K. A., Jang, C. J. H., Larive, C. K., and BaileySerres, J. (2008). Selective mRNA translation coordinates energetic and metabolic adjustments to cellular oxygen deprivation and reoxygenation in Arabidopsis thaliana. Plant J. 56, 743-755. doi: 10.1111/j.1365-313X.2008. 03642.x

Branco-Price, C., Kawaguchi, R., Ferreira, R. B., and Bailey-Serres, J. (2005). Genome-wide analysis of transcript abundance and translation in Arabidopsis seedlings subjected to oxygen deprivation. Ann. Bot. 96, 647-660. doi: 10.1093/ aob/mci217

Brembu, T., Winge, P., Bones, A. M., and Yang, Z. (2006). A RHOse by any other name: a comparative analysis of animal and plant Rho GTPases. Cell Res. 16, 435-445. doi: 10.1038/sj.cr.7310055

Browning, K. S., and Bailey-Serres, J. (2015). Mechanism of cytoplasmic mRNA translation. Arab. Book Am. Soc. Plant Biol. 13:e0176. doi: 10.1199/tab.0176

Burke, J. E., and Williams, R. L. (2015). Synergy in activating class I PI3Ks. Trends Biochem. Sci. 40, 88-100. doi: 10.1016/j.tibs.2014.12.003

Burks, E. A., Bezerra, P. P., Le, H., Gallie, D. R., and Browning, K. S. (2001). Plant initiation factor 3 subunit composition resembles mammalian initiation factor 3 and has a novel subunit. J. Biol. Chem. 276, 2122-2131. doi: 10.1074/jbc. M007236200

Cai, H., Das, S., Kamimura, Y., Long, Y., Parent, C. A., and Devreotes, P. N. (2010). Ras-mediated activation of the TORC2-PKB pathway is critical for chemotaxis. J. Cell Biol. 190, 233-245. doi: 10.1083/jcb.201001129

Cai, W., and Andres, D. A. (2014). mTORC2 is required for rit-mediated oxidative stress resistance. PLoS ONE 9:e115602. doi: 10.1371/journal.pone.0115602

Calvo, S. E., Pagliarini, D. J., and Mootha, V. K. (2009). Upstream open reading frames cause widespread reduction of protein expression and are polymorphic among humans. Proc. Natl. Acad. Sci. U.S.A. 106, 7507-7512. doi: 10.1073/pnas. 0810916106
Charest, P. G., Shen, Z., Lakoduk, A., Sasaki, A. T., Briggs, S. P., and Firtel, R. A. (2010). A Ras signaling complex controls the RasC-TORC2 pathway and directed cell migration. Dev. Cell 18, 737-749. doi: 10.1016/j.devcel.2010.03.017

Chen, J., and Yang, Z. (2014). Novel ABP1-TMK auxin sensing system controls ROP GTPase-mediated interdigitated cell expansion in Arabidopsis. Small GTPases [Epub ahead of print]. doi: 10.4161/sgtp.29711

Chen, X., and Friml, J. (2014). Rho-GTPase-regulated vesicle trafficking in plant cell polarity. Biochem. Soc. Trans. 42, 212-218. doi: 10.1042/BST20130269

Choi, J., Chen, J., Schreiber, S. L., and Clardy, J. (1996). Structure of the FKBP12rapamycin complex interacting with the binding domain of human FRAP. Science 273, 239-242. doi: 10.1126/science.273.5272.239

Chresta, C. M., Davies, B. R., Hickson, I., Harding, T., Cosulich, S., Critchlow, S. E., et al. (2010). AZD8055 is a potent, selective, and orally bioavailable ATPcompetitive mammalian target of rapamycin kinase inhibitor with in vitro and in vivo antitumor activity. Cancer Res. 70, 288-298. doi: 10.1158/0008-5472. CAN-09-1751

Cuchalová, L., Kouba, T., Herrmannová, A., Dányi, I., Chiu, W., and Valášek, L. (2010). The RNA recognition motif of eukaryotic translation initiation factor $3 \mathrm{~g}$ ( $\mathrm{eIF} 3 \mathrm{~g}$ ) is required for resumption of scanning of posttermination ribosomes for reinitiation on GCN4 and together with eIF3i stimulates linear scanning. Mol. Cell. Biol. 30, 4671-4686. doi: 10.1128/MCB.00430-10

Dam, T. J. P., Zwartkruis, F. J. T., Bos, J. L., and Snel, B. (2011). Evolution of the TOR Pathway. J. Mol. Evol. 73, 209-220. doi: 10.1007/s00239-011-9469-9

De Tapia, M., Himmelbach, A., and Hohn, T. (1993). Molecular dissection of the cauliflower mosaic virus translation transactivator. EMBO J. 12, 3305-3314.

Deak, M., Casamayor, A., Currie, R. A., Peter Downes, C., and Alessi, D. R. (1999). Characterisation of a plant 3-phosphoinositide-dependent protein kinase-1 homologue which contains a pleckstrin homology domain. FEBS Lett. 451, 220-226. doi: 10.1016/S0014-5793(99)00556-6

Deng, K., Yu, L., Zheng, X., Zhang, K., Wang, W., Dong, P., et al. (2016). Target of rapamycin is a key player for auxin signaling transduction in Arabidopsis. Front. Plant Sci. 7:291. doi: 10.3389/fpls.2016.00291

Deprost, D., Truong, H.-N., Robaglia, C., and Meyer, C. (2005). An Arabidopsis homolog of RAPTOR/KOG1 is essential for early embryo development. Biochem. Biophys. Res. Commun. 326, 844-850. doi: 10.1016/j.bbrc.2004.11.117

Deprost, D., Yao, L., Sormani, R., Moreau, M., Leterreux, G., Nicolai, M., et al. (2007). The Arabidopsis TOR kinase links plant growth, yield, stress resistance and mRNA translation. EMBO Rep. 8, 864-870. doi: 10.1038/sj.embor.7401043

Deragon, J.-M., and Bousquet-Antonelli, C. (2015). The role of LARP1 in translation and beyond. Wiley Interdiscip. Rev. RNA 6, 399-417. doi: 10.1002/ wrna. 1282

Dharmasiri, N., Dharmasiri, S., and Estelle, M. (2005). The F-box protein TIR1 is an auxin receptor. Nature 435, 441-445. doi: 10.1038/nature03543

Díaz-Troya, S., Pérez-Pérez, M. E., Florencio, F. J., and Crespo, J. L. (2008). The role of TOR in autophagy regulation from yeast to plants and mammals. Autophagy 4, 851-865. doi: 10.4161/auto.6555

Díaz-Troya, S., Pérez-Pérez, M. E., Pérez-Martin, M., Moes, S., Jenoe, P., Florencio, F. J., et al. (2011). Inhibition of protein synthesis by TOR inactivation revealed a conserved regulatory mechanism of the BiP chaperone in Chlamydomonas. Plant Physiol 157, 730-741. doi: 10.1104/pp.111.179861

Ding, Z., Wang, B., Moreno, I., Dupláková, N., Simon, S., Carraro, N., et al. (2012). ER-localized auxin transporter PIN8 regulates auxin homeostasis and male gametophyte development in Arabidopsis. Nat. Commun. 3:941. doi: 10.1038/ ncomms1941

Dobrenel, T., Caldana, C., Hanson, J., Robaglia, C., Vincentz, M., Veit, B., et al. (2016). TOR signaling and nutrient sensing. Annu. Rev. Plant Biol. 67, 261-285. doi: 10.1146/043014-114648

Dobrenel, T., Marchive, C., Azzopardi, M., Clément, G., Moreau, M., Sormani, R., et al. (2013). Sugar metabolism and the plant target of rapamycin kinase: a sweet operaTOR? Front. Plant Sci. 4:93. doi: 10.3389/fpls.2013.00093

Dong, P., Xiong, F., Que, Y., Wang, K., Yu, L., Li, Z., et al. (2015). Expression profiling and functional analysis reveals that TOR is a key player in regulating photosynthesis and phytohormone signaling pathways in Arabidopsis. Front. Plant Sci. 6:677. doi: 10.3389/fpls.2015.00677

Duan, Q., Kita, D., Li, C., Cheung, A. Y., and Wu, H.-M. (2010). FERONIA receptor-like kinase regulates RHO GTPase signaling of root hair development. Proc. Natl. Acad. Sci. U.S.A. 107, 17821-17826. doi: 10.1073/pnas. 1005366107 
Fang, Y., Vilella-Bach, M., Bachmann, R., Flanigan, A., and Chen, J. (2001). Phosphatidic acid-mediated mitogenic activation of mTOR signaling. Science 294, 1942-1945. doi: 10.1126/science. 1066015

Fehér, A., and Lajkó, D. B. (2015). Signals fly when kinases meet Rho-of-plants (ROP) small G-proteins. Plant Sci. 237, 93-107. doi: 10.1016/j.plantsci.2015.05. 007

Floris, M., Bassi, R., Robaglia, C., Alboresi, A., and Lanet, E. (2013). Posttranscriptional control of light-harvesting genes expression under light stress. Plant Mol. Biol. 82, 147-154. doi: 10.1007/s11103-013-0046- Z

Friml, J., and Jones, A. R. (2010). Endoplasmic reticulum: the rising compartment in auxin biology. Plant Physiol. 154, 458-462. doi: 10.1104/pp.110.161380

Fu, Y., Gu, Y., Zheng, Z., Wasteneys, G., and Yang, Z. (2005). Arabidopsis interdigitating cell growth requires two antagonistic pathways with opposing action on cell morphogenesis. Cell 120, 687-700. doi: 10.1016/j.cell.2004.12.026

Fu, Y., Xu, T., Zhu, L., Wen, M., and Yang, Z. (2009). A ROP GTPase signaling pathway controls cortical microtubule ordering and cell expansion in Arabidopsis. Curr. Biol. 19, 1827-1832. doi: 10.1016/j.cub.2009.08.052

Galindo-Trigo, S., Gray, J. E., and Smith, L. M. (2016). Conserved Roles of CrRLK1L receptor-Like kinases in cell expansion and reproduction from algae to angiosperms. Front. Plant Sci. 7:1269. doi: 10.3389/fpls.2016.01269

Ganguly, A., Lee, S. H., Cho, M., Lee, O. R., Yoo, H., and Cho, H. T. (2010). Differential auxin-transporting activities of PIN-FORMED proteins in Arabidopsis root hair cells. Plant Physiol. 153, 1046-1061. doi: 10.1104/pp.110. 156505

Gao, Y., Zhang, Y., Zhang, D., Dai, X., Estelle, M., and Zhao, Y. (2015). Auxin binding protein $1(\mathrm{ABP} 1)$ is not required for either auxin signaling or Arabidopsis development. Proc. Natl. Acad. Sci. U.S.A. 112, 2275-2280. doi: $10.1073 /$ pnas. 1500365112

Garcia, D., Collier, S. A., Byrne, M. E., and Martienssen, R. A. (2006). Specification of leaf polarity in Arabidopsis via the trans-acting siRNA pathway. Curr. Biol. 16, 933-938. doi: 10.1016/j.cub.2006.03.064

Gehring, C. A., McConchie, R. M., Venis, M. A., and Parish, R. W. (1998). Auxin-binding-protein antibodies and peptides influence stomatal opening and alter cytoplasmic pH. Planta 205, 581-586. doi: 10.1007/s00425 0050359

González, A., and Hall, M. N. (2017). Nutrient sensing and TOR signaling in yeast and mammals. EMBO J. 36, 397-408. doi: 10.15252/embj.201696010

Gray, W. M., Kepinski, S., Rouse, D., Leyser, O., and Estelle, M. (2001). Auxin regulates SCF(TIR1)-dependent degradation of AUX/IAA proteins. Nature 414, 271-276. doi: 10.1038/35104500

Gu, Y., Chae, H.-D., Siefring, J. E., Jasti, A. C., Hildeman, D. A., and Williams, D. A. (2006). RhoH GTPase recruits and activates Zap70 required for T cell receptor signaling and thymocyte development. Nat. Immunol. 7, 1182-1190. doi: $10.1038 /$ ni1396

Hancock, J. F., Magee, A. I., Childs, J. E., and Marshall, C. J. (1989). All ras proteins are polyisoprenylated but only some are palmitoylated. Cell 57, 1167-1177. doi: 10.1016/0092-8674(89)90054-8

Hanfrey, C., Elliott, K. A., Franceschetti, M., Mayer, M. J., Illingworth, C., and Michael, A. J. (2005). A Dual upstream open reading frame-based autoregulatory circuit controlling polyamine-responsive translation. J. Biol. Chem. 280, 39229-39237. doi: 10.1074/jbc.M509340200

Hara, K., Maruki, Y., Long, X., Yoshino, K.-I., Oshiro, N., Hidayat, S., et al. (2002). Raptor, a binding partner of target of rapamycin (TOR), mediates TOR action. Cell 110, 177-189. doi: 10.1016/S0092-8674(02)00833-4

Hardtke, C. S., and Berleth, T. (1998). The Arabidopsis gene MONOPTEROS encodes a transcription factor mediating embryo axis formation and vascular development. EMBO J. 17, 1405-1411. doi: 10.1093/emboj/17.5.1405

Hatano, T., Morigasaki, S., Tatebe, H., Ikeda, K., and Shiozaki, K. (2015). Fission yeast Ryh1 GTPase activates TOR complex 2 in response to glucose. Cell Cycle 14, 848-856. doi: 10.1080/15384101.2014.1000215

Hayden, C. A., and Jorgensen, R. A. (2007). Identification of novel conserved peptide uORF homology groups in Arabidopsis and rice reveals ancient eukaryotic origin of select groups and preferential association with transcription factor-encoding genes. BMC Biol. 5:32. doi: 10.1186/1741-7007-5-32

Heitman, J., Movva, N. R., and Hall, M. N. (1991). Targets for cell cycle arrest by the immunosuppressant rapamycin in yeast. Science 253, 905-909. doi: 10.1126/ science. 1715094
Hématy, K., and Höfte, H. (2008). Novel receptor kinases involved in growth regulation. Curr. Opin. Plant Biol. 11, 321-328. doi: 10.1016/j.pbi.2008.02.008

Hertel, R. (1995). OPINIONAuxin binding protein 1 is a red herring. J. Exp. Bot. 46, 461-462. doi: 10.1093/jxb/46.5.461-a

Hinnebusch, A. G. (1997). Translational regulation of yeast GCN4 A WINDOW ON FACTORS THAT CONTROL INITIATOR-tRNA BINDING TO THE RIBOSOME. J. Biol. Chem. 272, 21661-21664. doi: 10.1074/jbc.272.35.21661

Hinnebusch, A. G. (2006). eIF3: a versatile scaffold for translation initiation complexes. Trends Biochem. Sci. 31, 553-562. doi: 10.1016/j.tibs.2006.08.005

Hinnebusch, A. G., Ivanov, I. P., and Sonenberg, N. (2016). Translational control by 5'-untranslated regions of eukaryotic mRNAs. Science 352, 1413-1416. doi: $10.1126 /$ science.aad9868

Holz, M. K., Ballif, B. A., Gygi, S. P., and Blenis, J. (2005). mTOR and S6K1 mediate assembly of the translation preinitiation complex through dynamic protein interchange and ordered phosphorylation events. Cell 123, 569-580. doi: 10.1016/j.cell.2005.10.024

Hwang, J.-U., Vernoud, V., Szumlanski, A., Nielsen, E., and Yang, Z. (2008). A tip-localized Rho GTPase-activating protein controls cell polarity by globally inhibiting Rho GTPase at the cell apex. Curr. Biol. 18, 1907-1916. doi: 10.1016/ j.cub.2008.11.057

Inoki, K., Li, Y., Xu, T., and Guan, K.-L. (2003). Rheb GTPase is a direct target of TSC2 GAP activity and regulates mTOR signaling. Genes Dev. 17, 1829-1834. doi: $10.1101 /$ gad.1110003

Jacob, T., Ritchie, S., Assmann, S. M., and Gilroy, S. (1999). Abscisic acid signal transduction in guard cells is mediated by phospholipase D activity. Proc. Natl. Acad. Sci. U.S.A. 96, 12192-12197. doi: 10.1073/pnas.96.21.12192

Jewell, J. L., Kim, Y. C., Russell, R. C., Yu, F.-X., Park, H. W., Plouffe, S. W., et al. (2015). Differential regulation of mTORC1 by leucine and glutamine. Science 347, 194-198. doi: 10.1126/science. 1259472

Johnstone, T. G., Bazzini, A. A., and Giraldez, A. J. (2016). Upstream ORFs are prevalent translational repressors in vertebrates. EMBO J. 35, 706-723. doi: 10.15252/embj.201592759

Jones, M. A., Shen, J.-J., Fu, Y., Li, H., Yang, Z., and Grierson, C. S. (2002). The Arabidopsis Rop2 GTPase is a positive regulator of both root hair initiation and tip growth. Plant Cell 14, 763-776. doi: 10.1105/tpc.010359

Juntawong, P., and Bailey-Serres, J. (2012). dynamic light regulation of translation status in Arabidopsis thaliana. Front. Plant Sci. 3:66. doi: 10.3389/fpls.2012. 00066

Juntawong, P., Sorenson, R., and Bailey-Serres, J. (2013). Cold shock protein 1 chaperones mRNAs during translation in Arabidopsis thaliana. Plant J. 74, 1016-1028. doi: 10.1111/tpj.12187

Kawaguchi, R., and Bailey-Serres, J. (2005). mRNA sequence features that contribute to translational regulation in Arabidopsis. Nucleic Acids Res. 33, 955-965. doi: 10.1093/nar/gki240

Kawaguchi, R., Girke, T., Bray, E. A., and Bailey-Serres, J. (2004). Differential mRNA translation contributes to gene regulation under non-stress and dehydration stress conditions in Arabidopsis thaliana. Plant J. 38, 823-839. doi: 10.1111/j.1365-313X.2004.02090.x

Kelley, D. R., Arreola, A., Gallagher, T. L., and Gasser, C. S. (2012). ETTIN (ARF3) physically interacts with KANADI proteins to form a functional complex essential for integument development and polarity determination in Arabidopsis. Development 139, 1105-1109. doi: 10.1242/dev.067918

Kepinski, S., and Leyser, O. (2005). The Arabidopsis F-box protein TIR1 is an auxin receptor. Nature 435, 446-451. doi: 10.1038/nature03542

Khandal, D., Samol, I., Buhr, F., Pollmann, S., Schmidt, H., Clemens, S., et al. (2009). Singlet oxygen-dependent translational control in the tigrina-d.12 mutant of barley. Proc. Natl. Acad. Sci. U.S.A. 106, 13112-13117. doi: 10.1073/ pnas.0903522106

Khanna, A., Lotfi, P., Chavan, A. J., Montaño, N. M., Bolourani, P., Weeks, G., et al. (2016). The small GTPases Ras and Rap1 bind to and control TORC2 activity. Sci. Rep. 6:25823. doi: 10.1038/srep25823

Kim, D. H., Sarbassov, D. D., Ali, S. M., King, J. E., Latek, R. R., ErdjumentBromage, H., et al. (2002). mTOR interacts with raptor to form a nutrientsensitive complex that signals to the cell growth machinery. Cell 110, 163-175. doi: 10.1016/S0092-8674(02)00808-5

Kim, E., Goraksha-Hicks, P., Li, L., Neufeld, T. P., and Guan, K. L. (2008). Regulation of TORC1 by Rag GTPases in nutrient response. Nat. Cell Biol. 10, 935-945. doi: 10.1038/ncb1753 
Kim, T. H., Kim, B. H., Yahalom, A., Chamovitz, D. A., and von Arnim, A. G. (2004). Translational Regulation via 5' mRNA leader sequences revealed by mutational analysis of the Arabidopsis translation initiation factor Subunit eIF3h. Plant Cell 16, 3341-3356. doi: 10.1105/tpc.104.026880

Klahre, U., and Kost, B. (2006). Tobacco RhoGTPase ACTIVATING PROTEIN1 spatially restricts signaling of RAC/Rop to the apex of pollen tubes. Plant Cell 18, 3033-3046. doi: 10.1105/tpc.106.045336

Kozak, M. (1986). Point mutations define a sequence flanking the AUG initiator codon that modulates translation by eukaryotic ribosomes. Cell 44, 283-292. doi: 10.1016/0092-8674(86)90762-2

Kozak, M. (1987). Effects of intercistronic length on the efficiency of reinitiation by eucaryotic ribosomes. Mol. Cell. Biol. 7, 3438-3445. doi: 10.1128/MCB.7.10. 3438

Kozak, M. (1990). Downstream secondary structure facilitates recognition of initiator codons by eukaryotic ribosomes. Proc. Natl. Acad. Sci. U.S.A. 87, 8301-8305. doi: 10.1073/pnas.87.21.8301

Kozak, M. (1991). Structural features in eukaryotic mRNAs that modulate the initiation of translation. J. Biol. Chem. 266, 19867-19870.

Kozak, M. (1999). Initiation of translation in prokaryotes and eukaryotes. Gene 234, 187-208. doi: 10.1016/S0378-1119(99)00210-3

Kravchenko, A., Citerne, S., Jéhanno, I., Bersimbaev, R. I., Veit, B., Meyer, C., et al. (2015). Mutations in the Arabidopsis Lst8 and Raptor genes encoding partners of the TOR complex, or inhibition of TOR activity decrease abscisic acid (ABA) synthesis. Biochem. Biophys. Res. Commun. 467, 992-997. doi: 10.1016/j.bbrc. 2015.10.028

Kunz, J., Henriquez, R., Schneider, U., Deuter-Reinhard, M., Movva, N. R., and Hall, M. N. (1993). Target of rapamycin in yeast, TOR2, is an essential phosphatidylinositol kinase homolog required for G1 progression. Cell 73, 585-596. doi: 10.1016/0092-8674(93)90144-F

Lavy, M., and Estelle, M. (2016). Mechanisms of auxin signaling. Development 143, 3226-3229. doi: 10.1242/dev.131870

Leiber, R. M., John, F., Verhertbruggen, Y., Diet, A., Knox, J. P., and Ringli, C. (2010). The TOR pathway modulates the structure of cell walls in Arabidopsis. Plant Cell 22, 1898-1908. doi: 10.1105/tpc.109.073007

Levin, D. E. (2005). cell wall integrity signaling in Saccharomyces cerevisiae. Microbiol. Mol. Biol. Rev. 69, 262-291. doi: 10.1128/MMBR.69.2.262-291.2005

Leyser, O. (2006). Dynamic integration of auxin transport and signalling. Curr. Biol. 16, R424-R433. doi: 10.1016/j.cub.2006.05.014

Li, G., and Xue, H.-W. (2007). Arabidopsis PLDzeta2 regulates vesicle trafficking and is required for auxin response. Plant Cell 19, 281-295. doi: 10.1105/tpc.106. 041426

Li, H., Lin, Y., Heath, R. M., Zhu, M. X., and Yang, Z. (1999). Control of pollen tube tip growth by a Rop GTPase-dependent pathway that leads to tip-localized calcium influx. Plant Cell 11, 1731-1742. doi: 10.1105/tpc.11.9.1731

Li, X., Cai, W., Liu, Y., Li, H., Fu, L., Liu, Z., et al. (2017). Differential TOR activation and cell proliferation in Arabidopsis root and shoot apexes. Proc. Natl. Acad. Sci. U.S.A. 114, 2765-2770. doi: 10.1073/pnas.1618782114

Liu, Y., and Bassham, D. C. (2010). TOR is a negative regulator of autophagy in Arabidopsis thaliana. PLoS ONE 5:e11883. doi: 10.1371/journal.pone.0011883

Loewith, R., Jacinto, E., Wullschleger, S., Lorberg, A., Crespo, J. L., Bonenfant, D., et al. (2002). Two TOR complexes, only one of which is rapamycin sensitive, have distinct roles in cell growth control. Mol. Cell. 10, 457-468. doi: 10.1016/ S1097-2765(02)00636-6

Long, X., Lin, Y., Ortiz-Vega, S., Yonezawa, K., and Avruch, J. (2005). Rheb binds and regulates the mTOR kinase. Curr. Biol. 15, 702-713. doi: 10.1016/j.cub. 2005.02.053

Luttermann, C., and Meyers, G. (2007). A bipartite sequence motif induces translation reinitiation in feline calicivirus RNA. J. Biol. Chem. 282, 7056-7065. doi: 10.1074/jbc.M608948200

Luttermann, C., and Meyers, G. (2009). The importance of interand intramolecular base pairing for translation reinitiation on a eukaryotic bicistronic mRNA. Genes Dev. 23, 331-344. doi: 10.1101/gad. 507609

Luukkonen, B. G., Tan, W., and Schwartz, S. (1995). Efficiency of reinitiation of translation on human immunodeficiency virus type 1 mRNAs is determined by the length of the upstream open reading frame and by intercistronic distance. J. Virol. 69, 4086-4094.
Ma, X. M., and Blenis, J. (2009). Molecular mechanisms of mTOR-mediated translational control. Nat. Rev. Mol. Cell Biol. 10, 307-318. doi: 10.1038/ nrm 2672

Maehama, T., Tanaka, M., Nishina, H., Murakami, M., Kanaho, Y., and Hanada, K. (2008). RalA functions as an indispensable signal mediator for the nutrientsensing system. J. Biol. Chem. 283, 35053-35059. doi: 10.1074/jbc.M805822200

Mahfouz, M. M., Kim, S., Delauney, A. J., and Verma, D. P. (2006). Arabidopsis TARGET OF RAPAMYCIN interacts with RAPTOR, which regulates the activity of S6 kinase in response to osmotic stress signals. Plant Cell 18, 477-490. doi: 10.1105/tpc.105.035931

Marin, E., Jouannet, V., Herz, A., Lokerse, A. S., Weijers, D., Vaucheret, H., et al. (2010). miR390, Arabidopsis TAS3 tasiRNAs, and their AUXIN RESPONSE FACTOR targets define an autoregulatory network quantitatively regulating lateral root growth. Plant Cell 22, 1104-1117. doi: 10.1105/tpc.109.072553

Martin, T. D., Chen, X.-W., Kaplan, R. E. W., Saltiel, A. R., Walker, C. L., Reiner, D. J., et al. (2014). Ral and Rheb GTPase activating proteins integrate mTOR and gtpase signaling in aging, autophagy, and tumor cell invasion. Mol. Cell. 53, 209-220. doi: 10.1016/j.molcel.2013.12.004

Matsuura, H., Takenami, S., Kubo, Y., Ueda, K., Ueda, A., Yamaguchi, M., et al. (2013). A computational and experimental approach reveals that the 5 “proximal region of the 5-"UTR has a Cis-regulatory signature responsible for heat stress-regulated mRNA translation in Arabidopsis. Plant Cell Physiol. 54, 474-483. doi: $10.1093 / \mathrm{pcp} / \mathrm{pcs} 189$

Medenbach, J., Seiler, M., and Hentze, M. W. (2011). Translational control via protein-regulated upstream open reading frames. Cell 145, 902-913. doi: 10.1016/j.cell.2011.05.005

Menand, B., Desnos, T., Nussaume, L., Berger, F., Bouchez, D., Meyer, C., et al. (2002). Expression and disruption of the Arabidopsis TOR (target of rapamycin) gene. Proc. Natl. Acad. Sci. U.S.A. 99, 6422-6427. doi: 10.1073/pnas.092141899

Michaelson, D., Silletti, J., Murphy, G., D’Eustachio, P., Rush, M., and Philips, M. R. (2001). Differential localization of Rho gtpases in live cells. J. Cell Biol. 152, 111-126. doi: 10.1083/jcb.152.1.111

Mockaitis, K., and Estelle, M. (2008). Auxin receptors and plant development: a new signaling paradigm. Annu. Rev. Cell Dev. Biol. 24, 55-80. doi: 10.1146/ annurev.cellbio.23.090506.123214

Mohammad, M. P., Munzarová Pondilièková, V., Zeman, J., Gunišová, S., and Valášek, L. S. (2017). In vivo evidence that eIF3 stays bound to ribosomes elongating and terminating on short upstream ORFs to promote reinitiation. Nucleic Acids Res. 45, 2658-2674. doi: 10.1093/nar/gkx049

Montané, M.-H., and Menand, B. (2013). ATP-competitive mTOR kinase inhibitors delay plant growth by triggering early differentiation of meristematic cells but no developmental patterning change. J. Exp. Bot. 64, 4361-4374. doi: $10.1093 /$ jxb/ert 242

Moreau, M., Azzopardi, M., Clément, G., Dobrenel, T., Marchive, C., Renne, C., et al. (2012). Mutations in the Arabidopsis homolog of LST8/GßL, a partner of the target of Rapamycin kinase, impair plant growth, flowering, and metabolic adaptation to long days. Plant Cell 24, 463-481. doi: 10.1105/tpc.111.091306

Mravec, J., Skùpa, P., Bailly, A., Hoyerová, K., Krecek, P., Bielach, A., et al. (2009). Subcellular homeostasis of phytohormone auxin is mediated by the ERlocalized PIN5 transporter. Nature 459, 1136-1140. doi: 10.1038/nature08066

Munzarová, V., Pánek, J., Gunišová, S., Dányi, I., Szamecz, B., and Valášek, L. S. (2011). Translation reinitiation relies on the interaction between eIF3a/TIF32 and progressively folded cis-Acting mRNA elements preceding short uORFs. PLoS Genet. 7:e1002137. doi: 10.1371/journal.pgen.1002137

Nagawa, S., Xu, T., and Yang, Z. (2010). RHO GTPase in plants. Small GTPases 1, 78-88. doi: 10.4161/sgtp.1.2.14544

Napier, R. M., David, K. M., and Perrot-Rechenmann, C. (2002). A short history of auxin-binding proteins. Plant Mol. Biol. 49, 339-348. doi: 10.1023/A: 1015259130955

Nishimura, T., Wada, T., Yamamoto, K. T., and Okada, K. (2005). The Arabidopsis STV1 protein, responsible for translation reinitiation, is required for auxinmediated gynoecium patterning. Plant Cell 17, 2940-2953. doi: 10.1105/tpc.105. 036533

Nukarinen, E., Nägele, T., Pedrotti, L., Wurzinger, B., Mair, A., Landgraf, R., et al. (2016). Quantitative phosphoproteomics reveals the role of the AMPK plant ortholog SnRK1 as a metabolic master regulator under energy deprivation. Sci. Rep. 6:31697. doi: 10.1038/srep31697 
Oh, W. J., Wu, C., Kim, S. J., Facchinetti, V., Julien, L.-A., Finlan, M., et al. (2010). mTORC2 can associate with ribosomes to promote cotranslational phosphorylation and stability of nascent Akt polypeptide. EMBO J. 29, 3939-3951. doi: 10.1038/emboj.2010.271

Park, H.-S., Himmelbach, A., Browning, K. S., Hohn, T., and Ryabova, L. A. (2001). A plant viral "reinitiation" factor interacts with the host translational machinery. Cell 106, 723-733. doi: 10.1016/S0092-8674(01)00487-1

Park, S. H., Chung, P. J., Juntawong, P., Bailey-Serres, J., Kim, Y. S., Jung, H., et al. (2012). Posttranscriptional control of photosynthetic mRNA decay under stress conditions requires 3' and 5' untranslated regions and correlates with differential polysome association in rice. Plant Physiol. 159, 1111-1124. doi: $10.1104 /$ pp.112.194928

Park, Y., Reyna-Neyra, A., Philippe, L., and Thoreen, C. C. (2017). mTORC1 balances cellular amino acid supply with demand for protein synthesis through post-transcriptional control of ATF4. Cell Rep. 19, 1083-1090. doi: 10.1016/j. celrep.2017.04.042

Parry, G., Calderon-Villalobos, L. I., Prigge, M., Peret, B., Dharmasiri, S., Itoh, H., et al. (2009). Complex regulation of the TIR1/AFB family of auxin receptors. Proc. Natl. Acad. Sci. U.S.A. 106, 22540-22545. doi: 10.1073/pnas.0911967106

Pearce, L. R., Komander, D., and Alessi, D. R. (2010). The nuts and bolts of AGC protein kinases. Nat. Publish. Group 11, 9-22. doi: 10.1038/nrm2822

Pitts, R. J., Cernac, A., and Estelle, M. (1998). Auxin and ethylene promote root hair elongation in Arabidopsis. Plant J. 16, 553-560. doi: 10.1046/j.1365-313x. 1998.00321.x

Pöyry, T. A. A., Kaminski, A., Connell, E. J., Fraser, C. S., and Jackson, R. J. (2007). The mechanism of an exceptional case of reinitiation after translation of a long ORF reveals why such events do not generally occur in mammalian mRNA translation. Genes Dev. 21, 3149-3162. doi: 10.1101/gad.439507

Pöyry, T. A. A., Kaminski, A., and Jackson, R. J. (2004). What determines whether mammalian ribosomes resume scanning after translation of a short upstream open reading frame? Genes Dev. 18, 62-75.

Qiu, J.-L., Jilk, R., Marks, M. D., and Szymanski, D. B. (2002). The Arabidopsis SPIKE1 gene is required for normal cell shape control and tissue development. Plant Cell 14, 101-118. doi: 10.1105/tpc.010346

Rahman, A., Hosokawa, S., Oono, Y., Amakawa, T., Goto, N., and Tsurumi, S. (2002). Auxin and ethylene response interactions during Arabidopsis root hair development dissected by auxin influx modulators. Plant Physiol. 130, 1908-1917. doi: 10.1104/pp.010546

Rahmani, F., Hummel, M., Schuurmans, J., Wiese-Klinkenberg, A., Smeekens, S., and Hanson, J. (2009). Sucrose control of translation mediated by an upstream open reading frame-encoded peptide. Plant Physiol. 150, 1356-1367. doi: 10.1104/pp.109.136036

Reinard, T., Achmus, H., Walther, A., Rescher, U., Klämbt, D., and Jacobsen, H. J. (1998). Assignment of the auxin binding abilities of ABP44 in gel. Plant Cell Physiol. 39, 874-878. doi: 10.1093/oxfordjournals.pcp.a029447

Ren, M., Venglat, P., Qiu, S., Feng, L., Cao, Y., Wang, E., et al. (2012). Target of rapamycin signaling regulates metabolism, growth, and life span in Arabidopsis. Plant Cell 24, 4850-4874. doi: 10.1105/tpc.112.107144

Roy, B., Vaughn, J. N., Kim, B.-H., Zhou, F., Gilchrist, M. A., and Arnim, A. G. V. (2010). The h subunit of eIF3 promotes reinitiation competence during translation of mRNAs harboring upstream open reading frames. RNA 16, 748-761. doi: 10.1261/rna.2056010

Royall, E., and Locker, N. (2016). Translational control during calicivirus infection. Viruses 8:104. doi: 10.3390/v8040104

Ruggero, D., and Pandolfi, P. P. (2003). Does the ribosome translate cancer? Nat. Rev. Cancer 3, 179-192. doi: 10.1038/nrc1015

Ryabova, L. A., Pooggin, M. M., and Hohn, T. (2006). Translation reinitiation and leaky scanning in plant viruses. Virus Res. 119, 52-62. doi: 10.1016/j.virusres. 2005.10.017

Sabatini, D. M., Erdjument-Bromage, H., Lui, M., Tempst, P., and Snyder, S. H. (1994). RAFT1: a mammalian protein that binds to FKBP12 in a rapamycindependent fashion and is homologous to yeast TORs. Cell 78, 35-43. doi: 10.1016/0092-8674(94)90570-3

Sachs, M. S., and Geballe, A. P. (2006). Downstream control of upstream open reading frames. Genes Dev. 20, 915-921. doi: 10.1101/gad.1427006

Saci, A., Cantley, L. C., and Carpenter, C. L. (2011). Rac1 regulates the activity of mTORC1 and mTORC2 and controls cellular size. Mol. Cell 42, 50-61. doi: 10.1016/j.molcel.2011.03.017
Sancak, Y., Peterson, T. R., Shaul, Y. D., Lindquist, R. A., Thoreen, C. C., BarPeled, L., et al. (2008). The Rag GTPases bind raptor and mediate amino acid signaling to mTORC1. Science 320, 1496-1501. doi: 10.1126/science.1157535

Schepetilnikov, M., Dimitrova, M., Mancera-Martínez, E., Geldreich, A., Keller, M., and Ryabova, L. A. (2013). TOR and S6K1 promote translation reinitiation of uORF-containing mRNAs via phosphorylation of eIF3h. EMBO J. 32, 1087-1102. doi: 10.1038/emboj.2013.61

Schepetilnikov, M., Kobayashi, K., Geldreich, A., Caranta, C., Robaglia, C., Keller, M., et al. (2011). Viral factor TAV recruits TOR/S6K1 signalling to activate reinitiation after long ORF translation. EMBO J. 30, 1343-1356. doi: 10.1038/emboj.2011.39

Schepetilnikov, M., Makarian, J., Srour, O., Geldreich, A., Yang, Z., Chicher, J., et al. (2017). GTPase ROP2 binds and promotes activation of target of rapamycin, TOR, in response to auxin. EMBO J. 36, 886-903. doi: 10.15252/ embj.201694816

Schiller, M. R. (2006). Coupling receptor tyrosine kinases to Rho GTPases-GEFs what's the link. Cell. Signal. 18, 1834-1843. doi: 10.1016/j.cellsig.2006.01.022

Sessions, A., Nemhauser, J. L., McColl, A., Roe, J. L., Feldmann, K. A., and Zambryski, P. C. (1997). ETTIN patterns the Arabidopsis floral meristem and reproductive organs. Development $124,4481-4491$.

Siddiqui, N., and Sonenberg, N. (2015). Signalling to eIF4E in cancer. Biochem. Soc. Trans. 43, 763-772. doi: 10.1042/BST20150126

Simonini, S., Deb, J., Moubayidin, L., Stephenson, P., Valluru, M., Freire-Rios, A., et al. (2016). A noncanonical auxin-sensing mechanism is required for organ morphogenesis in Arabidopsis. Genes Dev. 30, 2286-2296. doi: 10.1101/gad. 285361.116

Smithson, L. J., and Gutmann, D. H. (2016). Proteomic analysis reveals GIT1 as a novel mTOR complex component critical for mediating astrocyte survival. Genes Dev. 30, 1383-1388. doi: 10.1101/gad.279661.116

Sorek, N., Henis, Y. I., and Yalovsky, S. (2011). How prenylation and S-acylation regulate subcellular targeting and function of ROP GTPases. Plant Signal. Behav. 6, 1026-1029. doi: 10.4161/psb.6.7.15578

Sormani, R., Yao, L., Menand, B., Ennar, N., Lecampion, C., Meyer, C., et al. (2007). Saccharomyces cerevisiae FKBP12 binds Arabidopsis thaliana TOR and its expression in plants leads to rapamycin susceptibility. BMC Plant Biol. 7:26. doi: 10.1186/1471-2229-7-26

Strader, L. C., and Zhao, Y. (2016). Auxin perception and downstream events. Curr. Opin. Plant Biol. 33, 8-14. doi: 10.1016/j.pbi.2016.04.004

Tan, X., Calderon-Villalobos, L. I. A., Sharon, M., Zheng, C., Robinson, C. V., Estelle, M., et al. (2007). Mechanism of auxin perception by the TIR1 ubiquitin ligase. Nature 446, 640-645. doi: 10.1038/nature05731

Tao, L., Cheung, A. Y., and Wu, H. (2002). Plant rac-like gtpases are activated by auxin and mediate auxin-responsive gene expression. Plant Cell 14, 2745-2760. doi: $10.1105 /$ tpc. 006320

Tatebe, H., Morigasaki, S., Murayama, S., Zeng, C. T., and Shiozaki, K. (2010). Rabfamily GTPase regulates TOR complex 2 signaling in fission yeast. Curr. Biol. 20, 1975-1982. doi: 10.1016/j.cub.2010.10.026

Tcherkezian, J., Cargnello, M., Romeo, Y., Huttlin, E. L., Lavoie, G., Gygi, S. P., et al. (2014). Proteomic analysis of cap-dependent translation identifies LARP1 as a key regulator of 5'TOP mRNA translation. Genes Dev. 28, 357-371. doi: $10.1101 /$ gad.231407.113

Thiébeauld, O., Schepetilnikov, M., Park, H.-S., Geldreich, A., Kobayashi, K., Keller, M., et al. (2009). A new plant protein interacts with eIF3 and 60S to enhance virus-activated translation re-initiation. EMBO J. 28, 3171-3184. doi: 10.1038/emboj.2009.256

Thiel, G., Blatt, M. R., Fricker, M. D., White, I. R., and Millner, P. (1993). Modulation of $\mathrm{K}+$ channels in Vicia stomatal guard cells by peptide homologs to the auxin-binding protein C terminus. Proc. Natl. Acad. Sci. U.S.A. 90, 11493-11497. doi: 10.1073/pnas.90.24.11493

Tiruneh, B. S., Kim, B.-H., Gallie, D. R., Roy, B., and von Arnim, A. G. (2013). The global translation profile in a ribosomal protein mutant resembles that of an eIF3 mutant. BMC Biol. 11:123. doi: 10.1186/1741-7007-11-123

Turck, F., Zilbermann, F., Kozma, S. C., Thomas, G., and Nagy, F. (2004). Phytohormones participate in an S6 kinase signal transduction pathway in Arabidopsis. Plant Physiol. 134, 1527-1535. doi: 10.1104/pp.103. 035873

Ulmasov, T., Hagen, G., and Guilfoyle, T. J. (1997a). ARF1, a transcription factor that binds to auxin response elements. Science 276, 1865-1868. 
Ulmasov, T., Murfett, J., Hagen, G., and Guilfoyle, T. J. (1997b). Aux/IAA proteins repress expression of reporter genes containing natural and highly active synthetic auxin response elements. Plant Cell 9, 1963-1971. doi: 10.1105/tpc. 9.11.1963

Ulmasov, T., Liu, Z. B., Hagen, G., and Guilfoyle, T. J. (1995). Composite structure of auxin response elements. Plant Cell 7, 1611-1623. doi: 10.1105/tpc.7.10.1611

von Arnim, A. G., Jia, Q., and Vaughn, J. N. (2014). Regulation of plant translation by upstream open reading frames. Plant Sci. 214, 1-12. doi: 10.1016/j.plantsci. 2013.09.006

Walsh, D., Mathews, M. B., and Mohr, I. (2013). Tinkering with translation: protein synthesis in virus-infected cells. Cold Spring Harb. Perspect. Biol. 5:a012351. doi: 10.1101/cshperspect.a012351

Wethmar, K., Schulz, J., Muro, E. M., Talyan, S., Andrade-Navarro, M. A., and Leutz, A. (2016). Comprehensive translational control of tyrosine kinase expression by upstream open reading frames. Oncogene 35, 1736-1742. doi: 10.1038/onc.2015.233

Wethmar, K., Smink, J. J., and Leutz, A. (2010). Upstream open reading frames: molecular switches in (patho)physiology. Bioessays 32, 885-893. doi: 10.1002/ bies. 201000037

Wiczer, B. M., and Thomas, G. (2012). Phospholipase D and mTORC1: nutrients are what bring them together. Sci. Signal. 5:e13. doi: 10.1126/scisignal.2003019

Wiese, A., Elzinga, N., Wobbes, B., and Smeekens, S. (2004). A conserved upstream open reading frame mediates sucrose-induced repression of translation. Plant Cell 16, 1717-1729. doi: 10.1105/tpc.019349

Winge, P., Brembu, T., Kristensen, R., and Bones, A. M. (2000). Genetic structure and evolution of RAC-GTPases in Arabidopsis thaliana. Genetics 156, 1959-1971.

Wolf, S., and Höfte, H. (2014). Growth control: a saga of cell walls, ROS, and peptide receptors. Plant Cell 26, 1848-1856. doi: 10.1105/tpc.114.125518

Wu, G., Li, H., and Yang, Z. (2000). Arabidopsis RopGAPs are a novel family of Rho GTPase-activating proteins that require the $\mathrm{Cdc} 42 / \mathrm{Rac}$-interactive binding motif for rop-specific GTPase stimulation. Plant Physiol. 124, 1625-1636. doi: $10.1104 /$ pp.124.4.1625

Wu, H. M., Hazak, O., Cheung, A. Y., and Yalovsky, S. (2011). RAC/ROP GTPases and auxin signaling. Plant Cell 23, 1208-1218. doi: 10.1105/tpc.111.083907

Xiong, Y., McCormack, M., Li, L., Hall, Q., Xiang, C., and Sheen, J. (2013). GlucoseTOR signalling reprograms the transcriptome and activates meristems. Nature 496, 181-186. doi: 10.1038/nature12030

Xiong, Y., and Sheen, J. (2012). Rapamycin and glucose-target of rapamycin (TOR) protein signaling in plants. J. Biol. Chem. 287, 2836-2842. doi: 10.1074/jbc. M111.300749

Xu, Q., Liang, S., Kudla, J., and Luan, S. (1998). Molecular characterization of a plant FKBP12 that does not mediate action of FK506 and rapamycin. Plant J. 15, 511-519. doi: 10.1046/j.1365-313X.1998.00232.x

Xu, T., Dai, N., Chen, J., Nagawa, S., Cao, M., Li, H., et al. (2014). Cell surface ABP1-TMK auxin-sensing complex activates ROP GTPase signaling. Science 343, 1025-1028. doi: 10.1126/science. 1245125
Xu, T., Wen, M., Nagawa, S., Fu, Y., Chen, J.-G., Wu, M.-J., et al. (2010). Cell surface- and Rho GTPase-based auxin signaling controls cellular interdigitation in Arabidopsis. Cell 143, 99-110. doi: 10.1016/j.cell.2010.09.003

Yan, G., Lai, Y., and Jiang, Y. (2012). The TOR complex 1 is a direct target of Rho1 GTPase. Mol. Cell 45, 743-753. doi: 10.1016/j.molcel.2012. 01.028

Yang, H., Gong, R., and Xu, Y. (2012). Control of cell growth: Rag GTPases in activation of TORC1. Cell. Mol. Life Sci. 70, 2873-2885. doi: 10.1007/s00018012-1195-y

Yoon, M.-S., Rosenberger, C. L., Wu, C., Truong, N., Sweedler, J. V., and Chen, J. (2015). Rapid mitogenic regulation of the mTORC1 inhibitor, DEPTOR, by phosphatidic acid. Mol. Cell 58, 549-556. doi: 10.1016/j.molcel.2015. 03.028

Zhang, Z., Zhu, J.-Y., Roh, J., Marchive, C., Kim, S.-K., Meyer, C., et al. (2016). TOR signaling promotes accumulation of BZR1 to balance growth with carbon availability in Arabidopsis. Curr. Biol. 26, 1854-1860. doi: 10.1016/j.cub.2016. 05.005

Zhou, F., Roy, B., Dunlap, J. R., Enganti, R., and von Arnim, A. G. (2014). Translational control of Arabidopsis meristem stability and organogenesis by the eukaryotic translation factor eIF3h. PLoS ONE 9:e95396. doi: 10.1371/ journal.pone.0095396

Zhou, F., Roy, B., and von Arnim, A. G. (2010). Translation reinitiation and development are compromised in similar ways by mutations in translation initiation factor eIF3h and the ribosomal protein RPL24. BMC Plant Biol. 10:193. doi: 10.1186/1471-2229-10-193

Zinoviev, A., Hellen, C. U. T., and Pestova, T. V. (2015). Multiple mechanisms of reinitiation on bicistronic calicivirus mRNAs. Mol. Cell 57, 1059-1073. doi: 10.1016/j.molcel.2015.01.039

Zinzalla, V., Stracka, D., Oppliger, W., and Hall, M. N. (2011). Activation of mTORC2 by association with the ribosome. Cell 144, 757-768. doi: 10.1016/j. cell.2011.02.014

Zvereva, A. S., Golyaev, V., Turco, S., Gubaeva, E. G., Rajeswaran, R., Schepetilnikov, M. V., et al. (2016). Viral protein suppresses oxidative burst and salicylic acid-dependent autophagy and facilitates bacterial growth on virus-infected plants. New Phytol. 211, 1020-1034. doi: 10.1111/nph. 13967

Conflict of Interest Statement: The authors declare that the research was conducted in the absence of any commercial or financial relationships that could be construed as a potential conflict of interest.

Copyright (c) 2017 Schepetilnikov and Ryabova. This is an open-access article distributed under the terms of the Creative Commons Attribution License (CC BY). The use, distribution or reproduction in other forums is permitted, provided the original author(s) or licensor are credited and that the original publication in this journal is cited, in accordance with accepted academic practice. No use, distribution or reproduction is permitted which does not comply with these terms. 